\title{
Description of Grain Refinement by Dynamic Recrystallization Under Hot Compressions for As-Extruded 3Cr20Ni10W2 Heat-Resistant Alloy
}

\begin{abstract}
The dynamic recrystallization (DRX) behavior of as-extruded 3Cr20Ni10W2 heat-resistant alloy was investigated by hot compressions with a fixed height reduction of $60 \%$ over a temperature range from 1,203 to $1,403 \mathrm{~K}$ and a strain rate range from 0.01 to $10 \mathrm{~s}^{-1}$. Results show that DRX occurs more easily at lower temperatures and higher strain rates, the stress level increases significantly with the increase of deformation temperature or the decrease of strain rate. Under such wide range of deformation conditions the flow stress evolution generally indicates two characteristics: work hardening $(\mathrm{WH})$ followed by DRX, or by dynamic recovery (DRV). The variation of the average size of grains refined by DRX behavior in the alloy is characterized by linking the deformation conditions during hot compression process. At a fixed temperature, the average grain size linearly decreases with increasing strain rate in log scale. At a lower strain rate, the average grain size rapidly increases with increasing temperature, while it remains almost constant at strain rate of $10 \mathrm{~s}^{-1}$. At a higher strain rate, grain size data sets tend to be closer to the average size value, which indicates that as strain rate increases, the microstructures become more and more uniform. The effects of the temperatures and strain rates on the average grain size can be represented by Zener-Hollomon parameter, $Z$, and the relationships between the average grain size and $Z$ parameter can be described as a nonlinear equation, which indicates that the average grain size decreases with increasing $Z$ parameter. On the plot of average grain size $D_{A}-\ln Z$, the regions corresponding to DRV $(\ln Z \leq 77.9)$ and DRX (ln $Z>77.9)$ were clarified clearly.
\end{abstract}

\footnotetext{
*Corresponding author: Guo-Zheng Quan, School of Material Science and Engineering, Chongqing University, Chongqing 400044, China, E-mail: quanguozheng@cqu.edu.cn

An Mao: E-mail: 316088924@qq.com, Zhen-Yu Zou: E-mail: zzy0518@msn.cn, Gui-Chang Luo: E-mail: 951972314@qq.com, Jian-Ting Liang: E-mail: 838054514@qq.com, School of Material Science and Engineering, Chongqing University, Chongqing 400044, China
}

Keywords: dynamic recrystallization, flow stress, microstructure, grain size

PACS. 81. Materials science

DOI 10.1515/htmp-2014-0127

Received July 23, 2014; accepted October 16, 2014

\section{Introduction}

As a typical heat-resisting alloy, 3Cr20Ni10W2 is broadly dedicated to manufacturing the exhaust valves on diesel engine in the large marine industry. Heat-resisting alloy usually exhibits adequate high-temperature mechanical properties, excellent oxidation resistance, superior creep strength, excellent heat resistance and high corrosion resistance [1-4]. During a hot deformation process, the deformed metal undergoes three metallurgical phenomena, including work hardening (WH), dynamic recovery (DRV) and dynamic recrystallization (DRX), which influence the microstructures and mechanical properties of the metal [5-8]. 3Cr20Ni10W2 is an alloy with low level of stacking fault energy, dislocation cross-slip is difficult to occur in plastic deformation, and then DRX softening mechanism becomes dominant [9]. In recent years, a large amount of efforts have been carried out on modeling DRX kinetics. Quan et al. [10] constructed the modified Avrami-type equation for 3Cr20Ni10W2 alloy, and then investigated the relationships between processing variables and DRX volume fraction. Timoshenkov et al. [11] modeled the DRX kinetics in C-Mn micro-alloyed steel during thermo-mechanical treatment, and this model was adopted in cellular automata simulation to optimize the microstructure and properties. Puchi-Cabrera et al. [12] investigated the work-softening transient induced by DRX of a C-Mn steel deformed in a wide range of temperatures and strain rates, meanwhile an original constitutive description independent of the peak parameters exhibited on the flow curves was proposed in differential form. $\mathrm{Li}$ et al. [13] proposed a new crystal plasticity model of the DRX in two-phase titanium alloys during isothermal processing, in which the theories for dislocation density 
evolution and DRX were introduced and modified. Also, the detailed microstructural features, such as grain size and morphology, as well as the homogeneity in microstructure have been studied. Fang et al. [14] investigated the control of austenitic grain size in 3Cr20Ni10W2 alloy by heat treatment and hot deformation. Lin et al. [15, 16] investigated the effects of processing parameters on the dynamic recrystallized volume of 42CrMo steel and $\mathrm{Ni}$ based superalloy by metallurgical analysis. Haghdadi et al. [17] investigated the homogeneity in hardness and microstructure of a commercially pure aluminum processed by accumulative back extrusion. Zhu et al. [18] studied the grain growth and microstructure evolution of Ni76Cr19AlTiCo during hot compression, and a modified Hall-Petch equation was proposed to predict the mechanical properties of the deformed alloy. All in all, numerous works on the microstructure evolution have been developed, while the effect of deformation conditions on average grain size refined by DRX has not been paid enough attention.

In the present work, according to the conventional strain hardening rate curves (WH rate versus $\sigma$ ) and their derived results, the values of critical stress for DRX initiation have been identified, and their existence means the occurrence of DRX. The aim of this study is to exhibit the microstructure evolution by a series of metallographs, to uncover the flow stress softening mechanisms including DRX and DRV and then to describe the general nature of the influence of strain rate and temperature on the average size of grains refined by DRX under hot compression. The effects of temperature and strain rate on the average grain size are represented by Zener-Hollomon parameter, $Z$, in an exponent-type function of temperature and strain rate. Then the relationships between the average grain size and Zener-Hollomon parameter were nonlinearly fitted by the equation $D_{A}=40.83854+0.44614 \ln Z-$ $0.0076(\ln Z)^{2}$. Furthermore, on the plot of $D_{A} \ln Z$, the regions corresponding to DRV ( $\ln Z \leq 77.9)$ and DRX (ln $Z>77.9$ were clarified.

\section{Materials and experimental methods}

The as-extruded 3Cr20Ni10W2 heat-resisting alloy employed in the present investigation was received in the form of bar with the diameter of $100 \mathrm{~mm}$. The chemical compositions of the experimental alloy (wt\%) are as follows: C- 0.25 , Si-1, Cr-20, Ni-10, Mn-1, W-2, Fe (balance). Cylindrical specimens with an initial diameter of
$10 \mathrm{~mm}$ and a height of $12 \mathrm{~mm}$ were machined directly from the as-extruded bar, and 20 such specimens were machined with their cylinder axes parallel to the axial line direction of the bar. The 20 specimens were homogenized under temperature $1,373 \mathrm{~K}$ for $12 \mathrm{~h}$ to remove the microsegregation formed during casting and to obtain a uniform composition and organization. The time-temperature route used in this study is summarized in Figure 1. The isothermal compression tests were performed on Gleeble 1500 thermo-mechanical simulator. In this experiment, 20 specimens were resistance heated to the deformation temperature at a constant heating rate of $30 \mathrm{~K} / \mathrm{s}$ by thermo-coupled feedback-controlled AC current and held at a certain temperature for $180 \mathrm{~s}$ to ensure a uniform deformation temperature and decrease the material anisotropy. The compression tests corresponding to a height reduction ratio of $60 \%$ were carried out at five different temperatures of 1,203,1,253,1,303,1,353 and $1,403 \mathrm{~K}$, and four different strain rates of $0.01,0.1,1$ and $10 \mathrm{~s}^{-1}$. A height reduction of $60 \%$ was adopted due to the fact that DRX occurred almost complete under that deformation degree. The tantalum foil was used between the specimen and dies in order to minimize the frictions during hot deformation. After each compression, the deformed specimens were quenched by water to preserve the recrystallized microstructure pattern of high-temperature deformation [19]. Then all the deformed samples for metallographic analysis were sliced at mid-plane parallel to the longitudinal compression axis. The microstructures were examined in the center zone of the specimens (marked "X" in Figure 2(b)). The sections were polished and etched in an abluent solution of Kroll's reagent ( $\mathrm{HF}+\mathrm{HNO}_{3}+$ water) at room temperature. The optical microstructures in the center region of the section plane were observed.

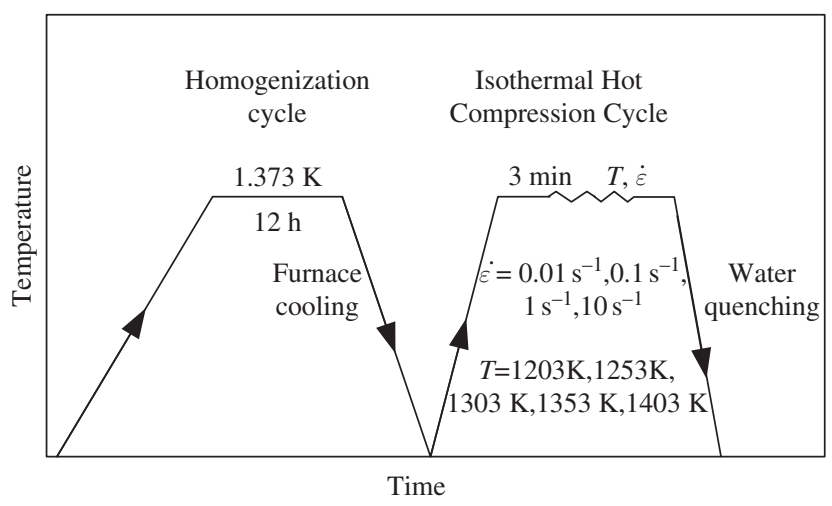

Figure 1: Schematic time-temperature diagrams for isothermal hot compression test. 


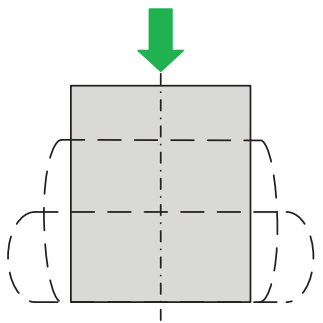

(a)

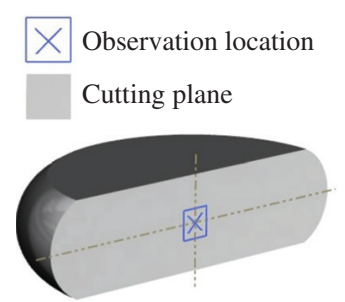

(b)
Figure 2: Schematic representation of the uniaxial compression specimen (a) before (arrow indicates the applied load direction) and (b) after the testing (section with hatch pattern shows the cut plane and region marked " $X$ " indicates the observation location).

The stress-strain data were recorded by a personal computer equipped with an automatic data acquisition system during the hot compression. The true stress and true strain were derived from the measurement of nominal stress-strain relationship according to the following formula: $\sigma_{\mathrm{T}}=\sigma_{\mathrm{N}}\left(1+\varepsilon_{\mathrm{N}}\right), \varepsilon_{\mathrm{T}}=\ln \left(1+\varepsilon_{\mathrm{N}}\right)$, where $\sigma_{\mathrm{T}}$ is the true stress, $\sigma_{\mathrm{N}}$ is the nominal strain, $\varepsilon_{\mathrm{T}}$ is the true strain and $\varepsilon_{\mathrm{N}}$ is the nominal strain $[8,20]$.

\section{Results and discussion}

\section{Characteristics of softening flow behavior coupling with DRX}

Using true stress-strain data, the true compressive stress-strain curves of 3Cr20Ni10W2 alloy are developed and shown as Figure 3(a)-(d). The stress-strain data in Figure 3(a)-(d) was analyzed by fitting each experimental curve with a polynomial function and taking its derivative with respect to strain to obtain the $\mathrm{WH}$ rate. Then, the WH rate $(\theta=\mathrm{d} \sigma / \mathrm{d} \varepsilon)$ was plotted against flow stress $(\sigma)$ as shown in Figure 4(a)-(d). For a given strain, the $\mathrm{WH}$ rate is the derivative of stress with respect to strain $(\varepsilon)$, which corresponds to the tangent at this strain value. From all the $\theta$ versus $\sigma$ curves in Figure 4(a)-(d), it can be summarized that the stress evolution with strain obviously exhibits three distinct stages. In the first and the second stages, $\theta$-values are positive which indicate WH characteristics. While in the third stage, $\theta$-values exhibit two types of variation tendency such as negative

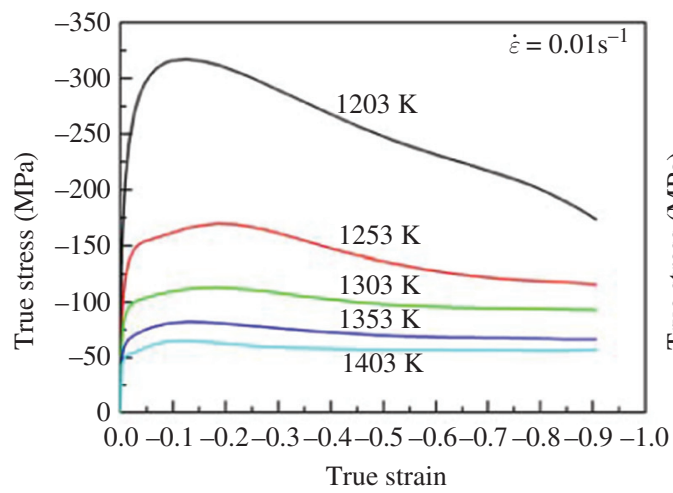

(a)

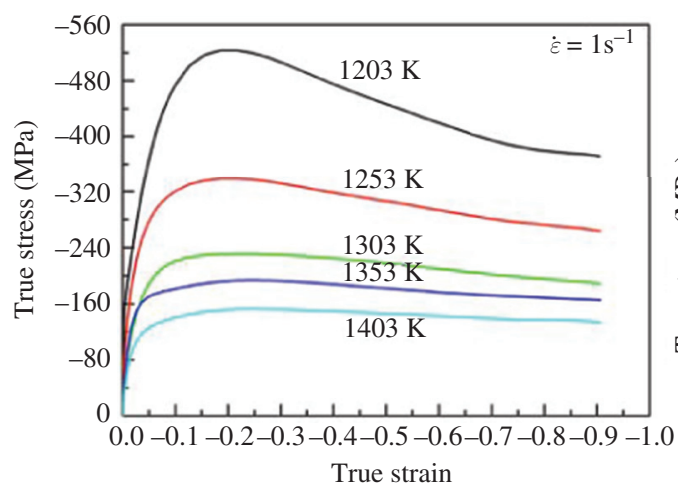

(c)

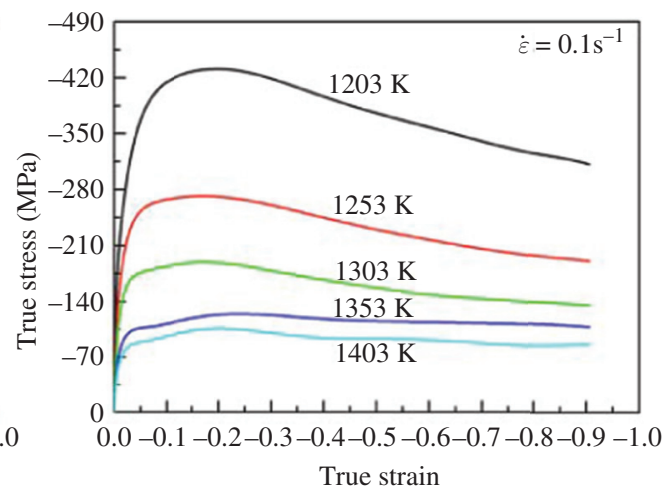

(b)

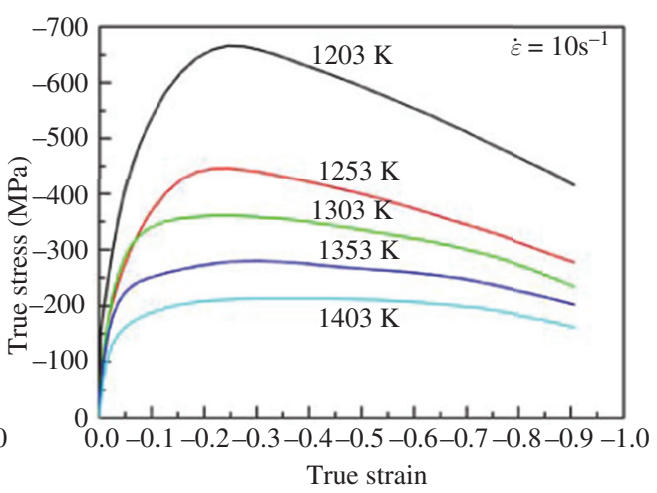

(d)

Figure 3: True stress-strain curves of as-extruded 3Cr20Ni10W2 heat-resisting alloy obtained by Gleeble 1500 under the different deformation temperatures with strain rates: (a) $0.01 \mathrm{~s}^{-1}$, (b) $0.1 \mathrm{~s}^{-1}$, (c) $1 \mathrm{~s}^{-1}$, (d) $10 \mathrm{~s}^{-1}$. 


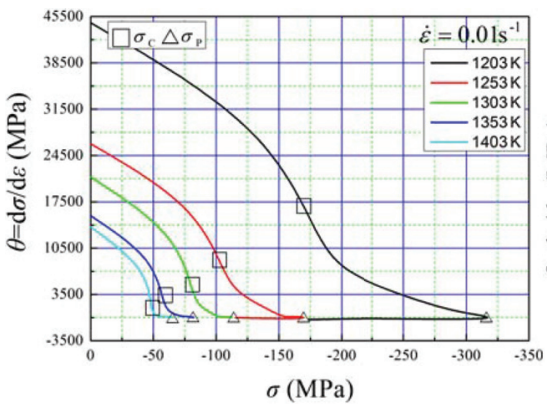

(a)

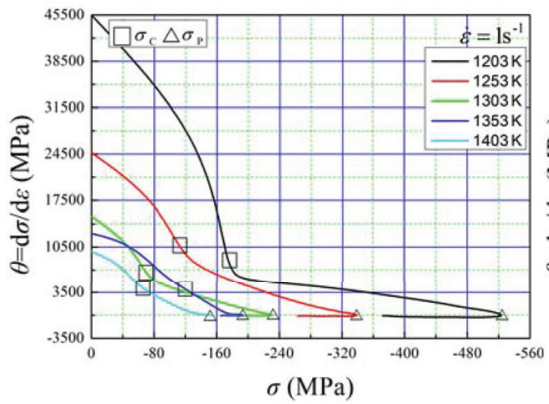

(c)

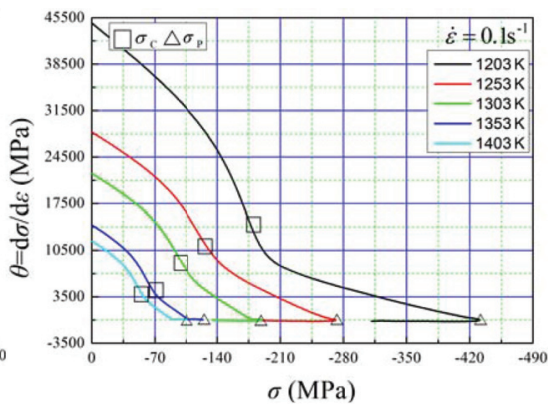

(b)

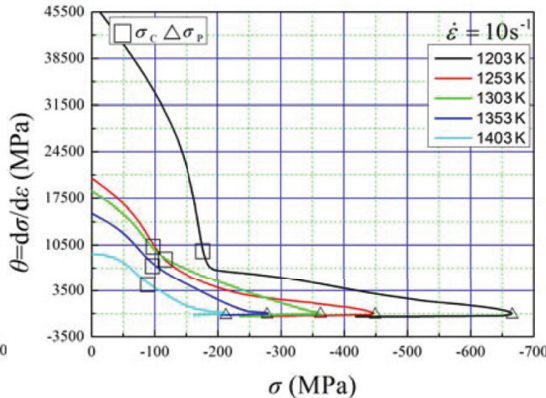

(d)

Figure 4: $\theta=d \sigma / d \varepsilon$ versus $\sigma$ plots under different deformation temperatures with strain rates: (a) $0.01 \mathrm{~s}^{-1}$, (b) $0.1 \mathrm{~s}^{-1}$, (c) $1 \mathrm{~s}^{-1}$, (d) $10 \mathrm{~s}^{-1}$.

variables with $\sigma$, and almost positive constants. Negative variables represent the predominance of DRX softening. Positive constants represent balance between dominant DRV softening and WH. Furthermore, the types of flow stress evolution were distinguished by the following two characteristics: WH followed by DRX and DRV.

At the first stage where WH predominates, flow stress exhibits a rapid increase (i.e. relatively large $\theta$-value) to a critical value $\left(\sigma_{\mathrm{C}}\right)$ with increasing strain, meanwhile the stored energy in the grain boundaries originates from a large difference in dislocation density within subgrains or grains and grows rapidly to DRX activation energy. The critical stress for DRX is attained when the value of $|-\mathrm{d} \theta / \mathrm{d} \sigma|$ (as shown in Figure 5(d)), where strain hardening rate $\theta=\mathrm{d} \sigma / \mathrm{d} \varepsilon$, reaches the minimum which corresponds to an inflection of $\mathrm{d} \sigma / \mathrm{d} \varepsilon$ versus $\sigma$ curve (Figure 5(b) and (c)). When the critical driving force is attained, new grains are nucleated along the grain boundaries, deformation bands and dislocations, resulting in equiaxed DRX grains. At the second stage, flow stress exhibits a smaller and smaller increase until a peak value $\left(\sigma_{\mathrm{P}}\right)$ with a relatively small $\theta$-value. At the beginning of the second stage, the critical driving force of DRX has been attained, and then new equiaxed grains are nucleated along the original grain boundaries. The onset of DRX softening mechanism induces an obvious inflection of $\mathrm{WH}$ rate. At the third stage, as $\sigma$-value decreases below $\sigma_{\mathrm{p}}, \theta$-value becomes negative, which means that the thermal softening exceeds $\mathrm{WH}$ and becomes predominant. At this stage, three types of $\theta$ versus $\sigma$ curve variation tendency can be generalized as follows. As for the first type corresponding to the deformation conditions of 1,203-1,253 $\mathrm{K}$ and $0.01 \mathrm{~s}^{-1}, 1,203-$ $1,303 \mathrm{~K}$ and $0.1 \mathrm{~s}^{-1}, 1,203-1,353 \mathrm{~K}$ and $1 \mathrm{~s}^{-1}, 1,203-1,403 \mathrm{~K}$ and $10 \mathrm{~s}^{-1}, \theta$-value increases up to the negative peak which corresponds to a valley point of $\theta$ versus $\sigma$ plot, and then, $\theta$-value decreases to zero which corresponds to the onset of a steady-state flow as a plateau (a balance between dominant DRX softening and WH) in stressstrain curve. As for the second type corresponding to the deformation conditions of 1,303-1,403 $\mathrm{K}$ and $0.01 \mathrm{~s}^{-1}, 1,353-1,403 \mathrm{~K}$ and $0.1 \mathrm{~s}^{-1}, 1,403 \mathrm{~K}$ and $1 \mathrm{~s}^{-1}$, $\theta$-value always maintains a steady state that indicates the balance between dominant DRV softening and WH.

The analysis after the hot compression tests reveals that during the hot compression, the microstructures and mechanical properties of 3Cr20Ni10W2 heat-resisting alloy are influenced by three metallurgical phenomena including WH, DRV and DRX. DRV induces the fact that flow stress saturates after an initial period of WH. This saturation value depends on temperature, strain rate and composition. During DRV, the original grains get increasingly strained, but the sub-boundaries remain more or less equiaxed. This implies that the substructure is "dynamic" and readapts continuously to the increasing strain. At a critical strain, and correspondingly at a 


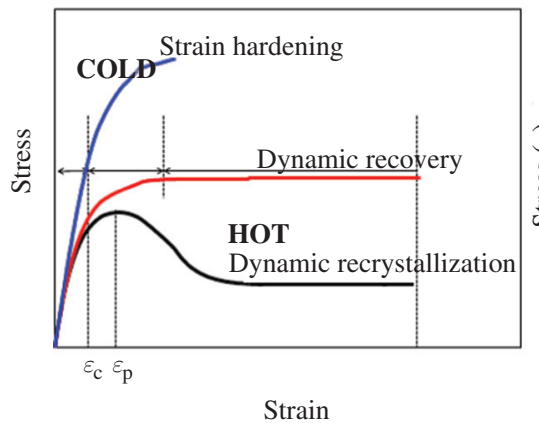

(a)

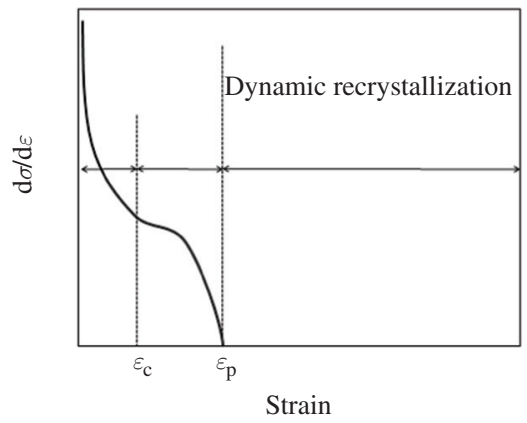

(c)

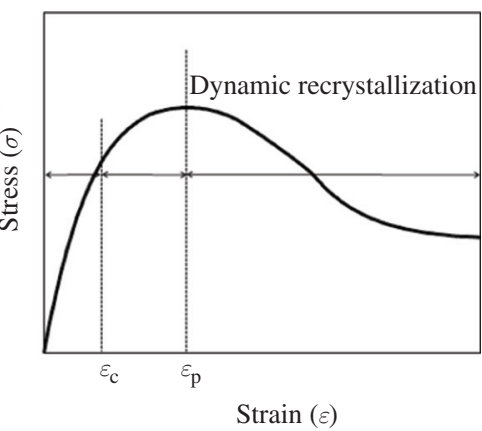

(b)

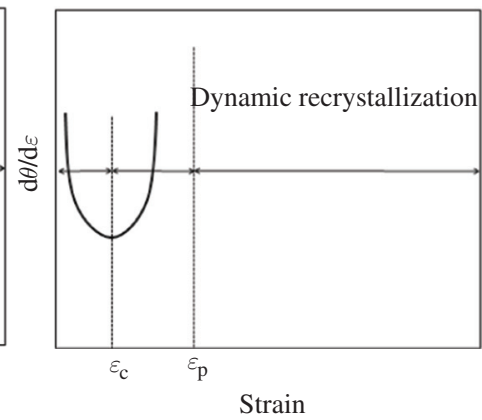

(d)

Figure 5: The typical and ideal schematic diagram for measuring the critical stress: (a) typical flow curves during cold and hot deformation, (b) $\sigma$ versus $\varepsilon$ plots, (c) $\theta=\mathrm{d} \sigma / \mathrm{d} \varepsilon$ versus $\varepsilon$ plots, (d) $\mathrm{d} \theta / \mathrm{d} \varepsilon$ versus $\varepsilon$ plots.

value/variation in driving force, dynamically recrystallized grains appear at the original grain boundaries, which results in the so-called necklace structure [21, 22]. With further deformation, more and more potential nuclei are activated and new recrystallized grains appear [23, 24]. At the same time, the grains, which had already recrystallized in a previous stage, are deformed again. After a certain amount of strain, typical equilibrium is reached between the hardening due to dislocation accumulation and the softening due to DRX. At this stage, the flow curve reaches a plateau, and the microstructure consists of a dynamic mixture of grains with various dislocation densities [25].

\section{Microstructure observation}

The exposed surfaces on the section plane of specimen deformed to the true strain of -0.9 were observed and analyzed using the optical microscope (OM). Figure 6 shows the initial microstructure of as-extruded 3Cr20Ni10W2 heat-resisting alloy specimen with a facecentered cubic structure and a homogeneous aggregate of rough equiaxed polygonal grains (the grain boundaries are straight to gently curved and often intersect at $\sim 120^{\circ}$ triple junctions), while with a few coarse particles. The main precipitate in 3Cr20Ni10W2 heat-resisting alloy is $\gamma$-phase $\mathrm{M}_{23} \mathrm{C}_{6}$-type carbides, which is the typical secondary phase in majority of the Cr-containing austenitic stainless steels [1-3, 26-28], randomly precipitated inside the grains and partially at grain boundaries. The amount of precipitates in the microstructures indicates an important influence on the characteristic properties of austenitic steels: hardness and resistance to corrosion, abrasion and wear. Figures 7-11 show the typical microstructures of the specimens of as-extruded 3Cr20Ni10W2 heatresisting alloy deformed to a strain of -0.9 at the temperature of 1,203-1,403 $\mathrm{K}$ and at the strain rates of $0.01-$ $10 \mathrm{~s}^{-1}$, respectively. Generally, temperatures have obvious effects on the precipitation of $\mathrm{M}_{23} \mathrm{C}_{6}$-type carbides [29]. In the present work, the carbides inside the grains and along the grain boundaries can be identified at the temperature of 1,203 and 1,253 $\mathrm{K}$, while no carbides can be observed when the deformation temperature is higher than $1,303 \mathrm{~K}$.

In Figures 7-11 DRX grains have been marked. The deformed metal completely or partially transforms to a microstructure of approximately equiaxed defect-free grains which are predominantly bounded by high angle boundaries (i.e. a recrystallized microstructure) by relatively localized boundary migration. The results of microstructure observation imply the levels of dynamically 


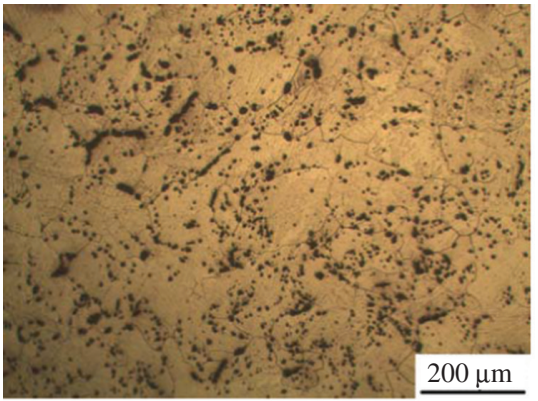

(a)

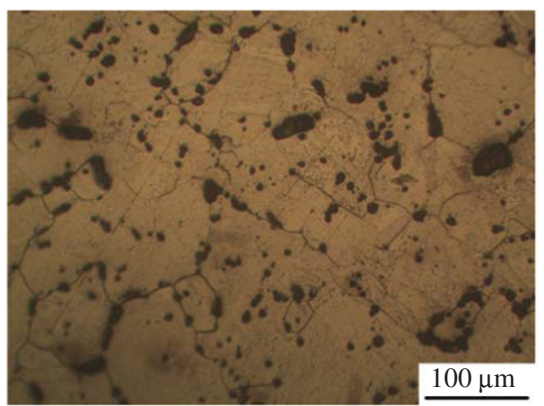

(c)

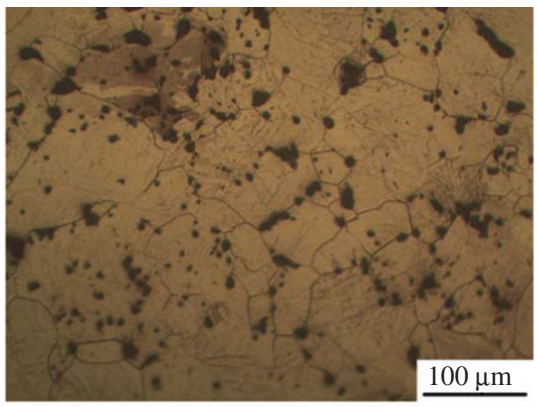

(b)

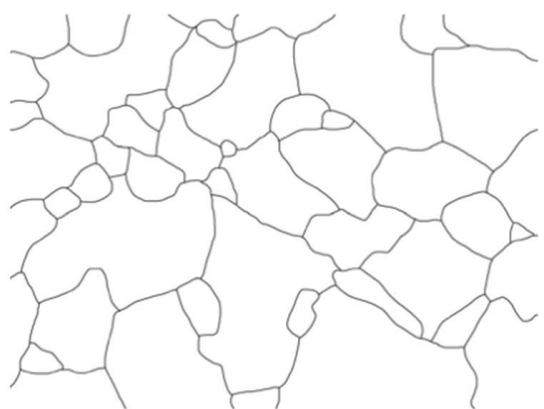

(d)

Figure 6: Optical microstructures and average grain size of as-extruded 3Cr20Ni10W2 heat-resisting alloy undeformed (starting material).

recrystallized volume fractions, and such levels can be roughly and indirectly estimated by the following statistical analysis of the average grain size due to the fact that smaller average grain size means larger volume fraction of DRX as DRX makes the original equiaxed grains refined.
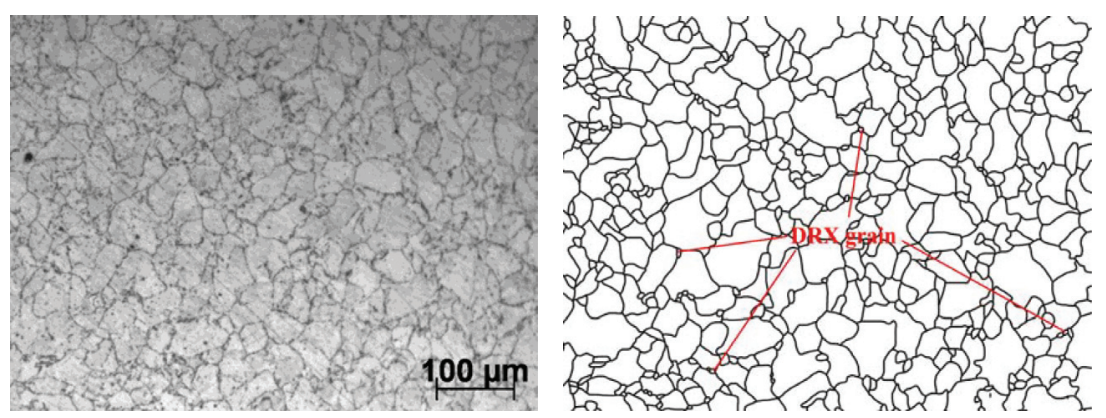

(a)
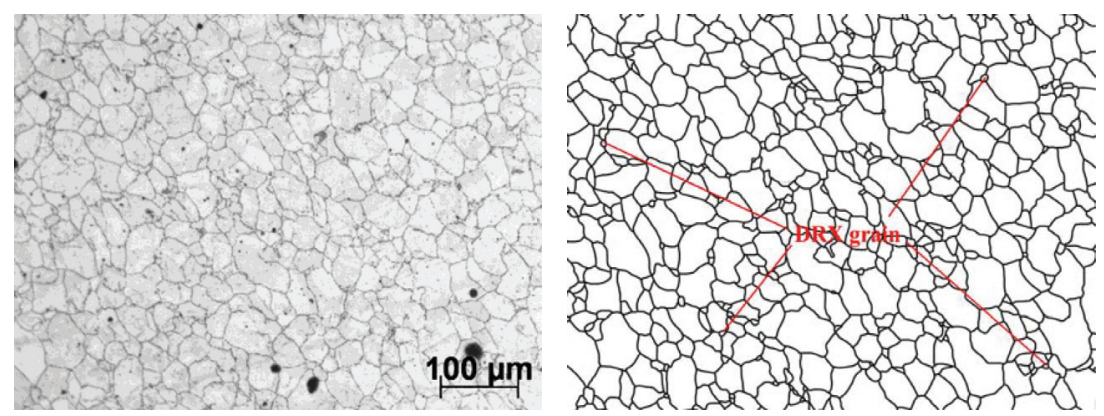

(b)

Figure 7: Optical microstructures of as-extruded 3Cr20Ni10W2 heat-resisting alloy at a fixed true strain of -0.9 , a fixed temperature of $1,203 \mathrm{~K}$ and different strain rates: (a) $0.01 \mathrm{~s}^{-1}$, (b) $0.1 \mathrm{~s}^{-1}$, (c) $1 \mathrm{~s}^{-1}$, (d) $10 \mathrm{~s}^{-1}$. 

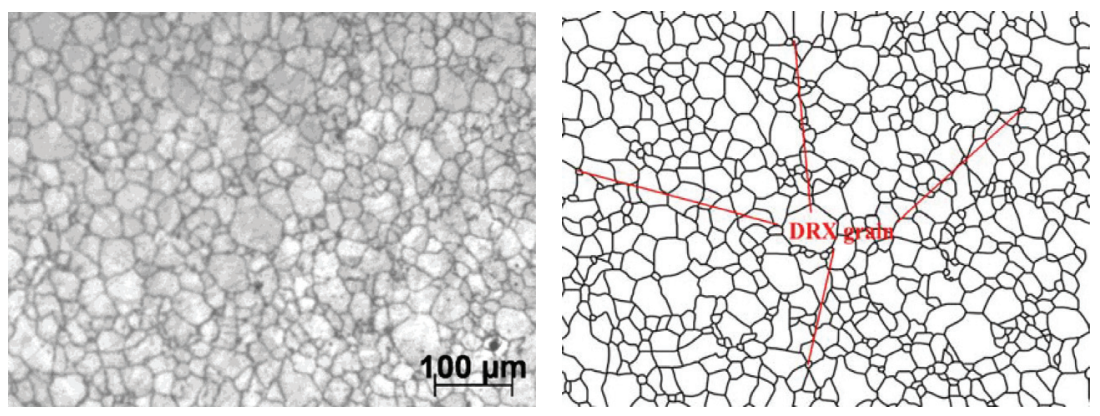

(c)

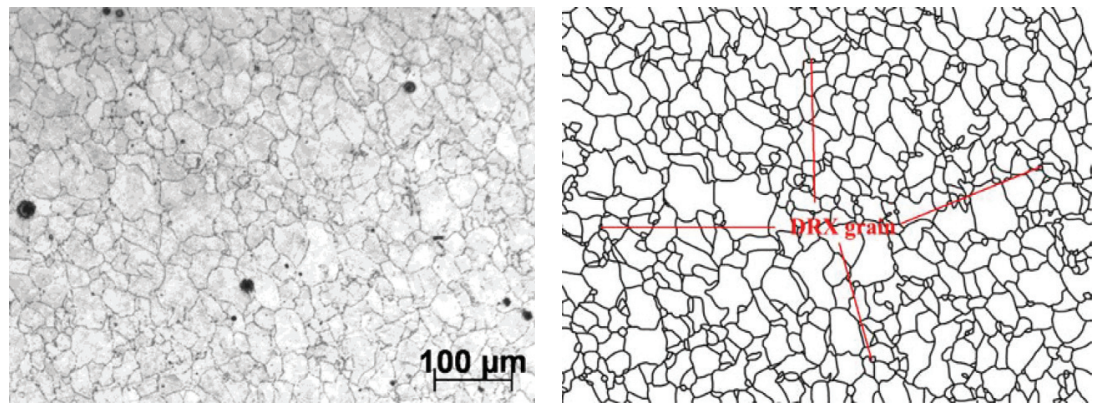

(d)

Figure 7: (Continued).
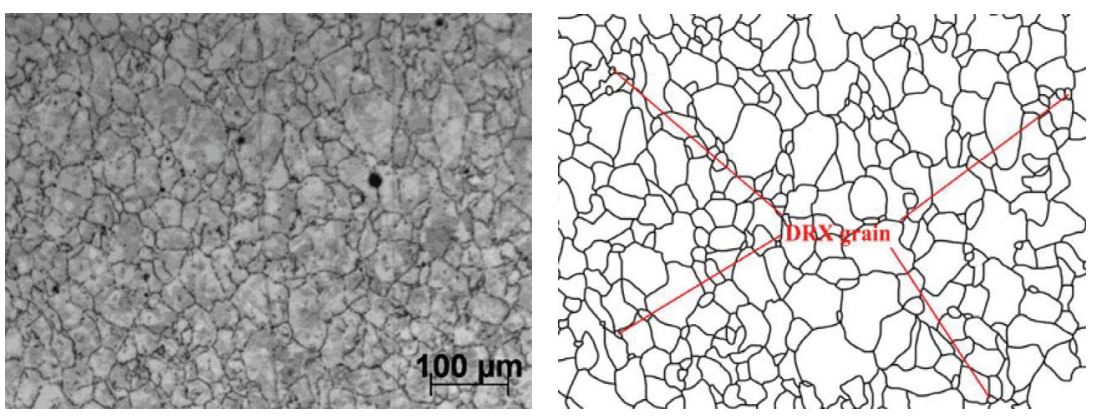

(a)
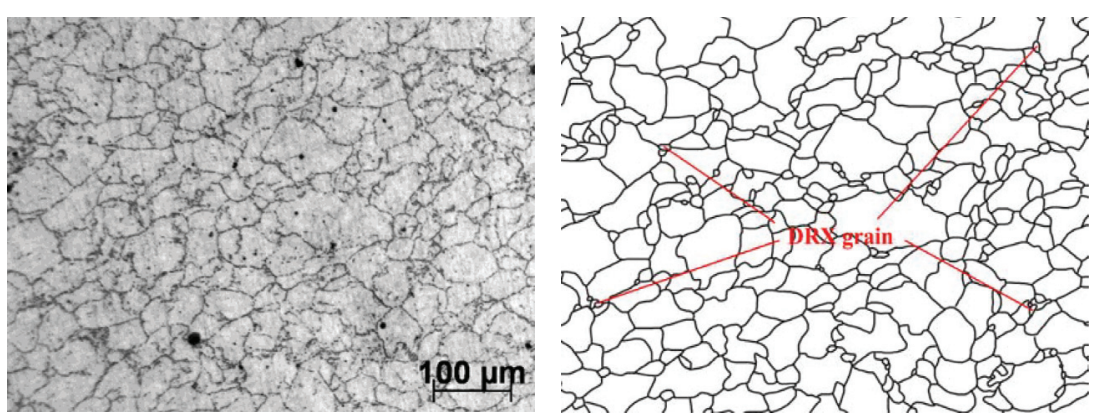

(b)

Figure 8: Optical microstructures of as-extruded 3Cr20Ni10W2 heat-resisting alloy at a fixed true strain of -0.9 , a fixed temperature of $1,253 \mathrm{~K}$ and different strain rates: (a) $0.01 \mathrm{~s}^{-1}$, (b) $0.1 \mathrm{~s}^{-1}$, (c) $1 \mathrm{~s}^{-1}$, (d) $10 \mathrm{~s}^{-1}$. 

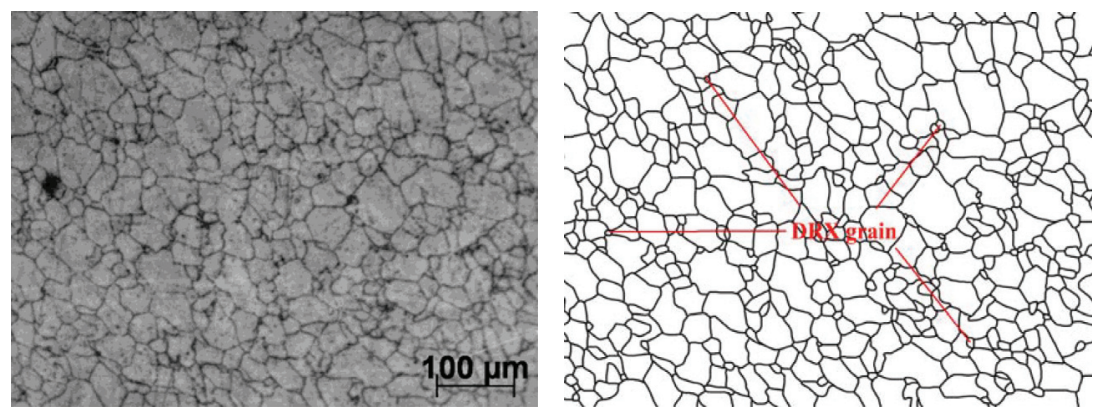

(c)
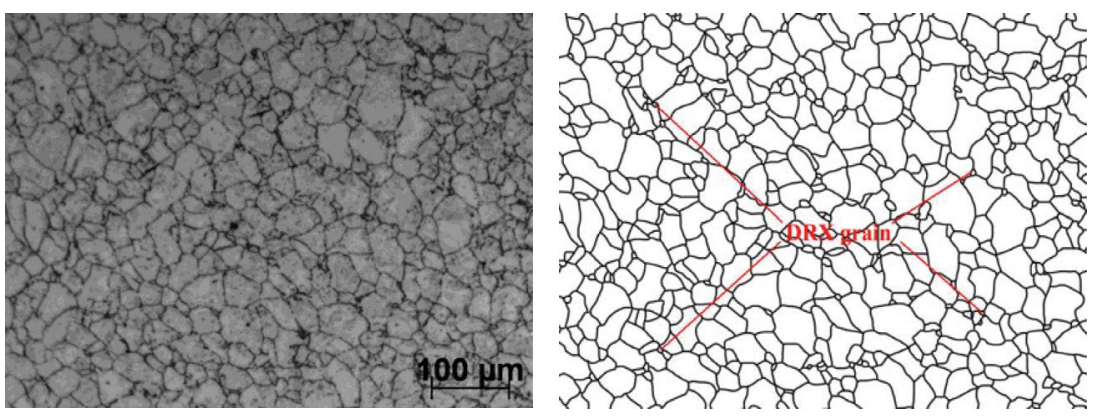

(d)

Figure 8: (Continued).
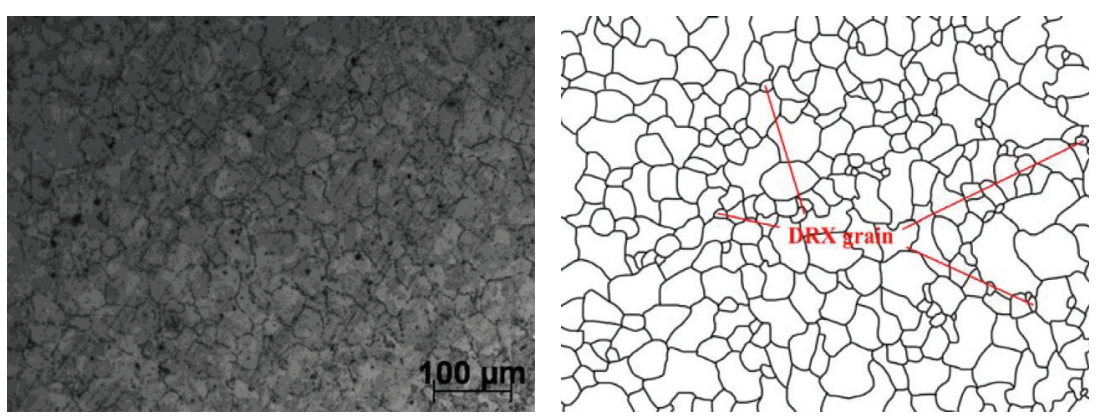

(a)
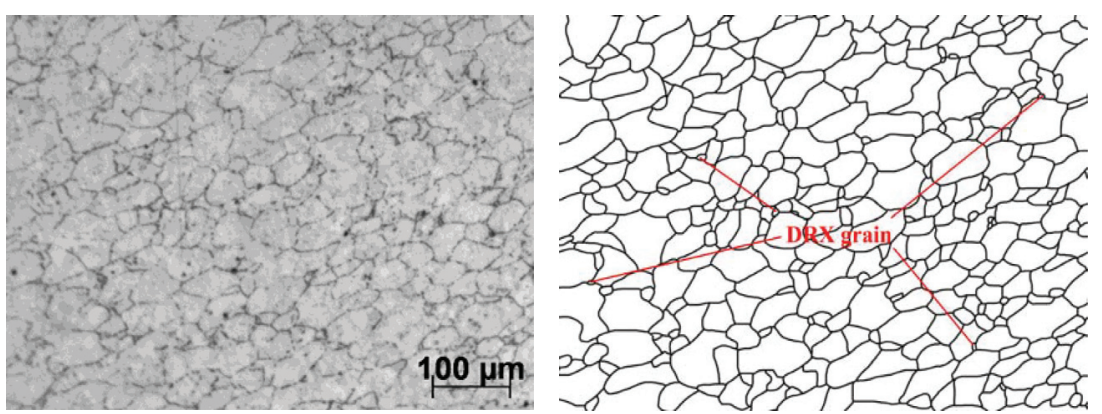

(b)

Figure 9: Optical microstructures of as-extruded 3Cr20Ni10W2 heat-resisting alloy at a fixed true strain of -0.9 , a fixed temperature of $1,303 \mathrm{~K}$ and different strain rates: (a) $0.01 \mathrm{~s}^{-1}$, (b) $0.1 \mathrm{~s}^{-1}$, (c) $1 \mathrm{~s}^{-1}$, (d) $10 \mathrm{~s}^{-1}$. 

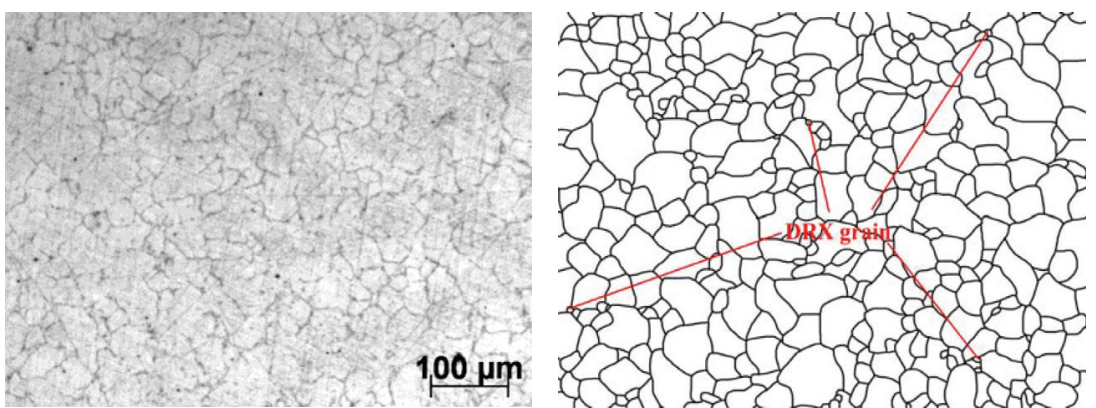

(c)
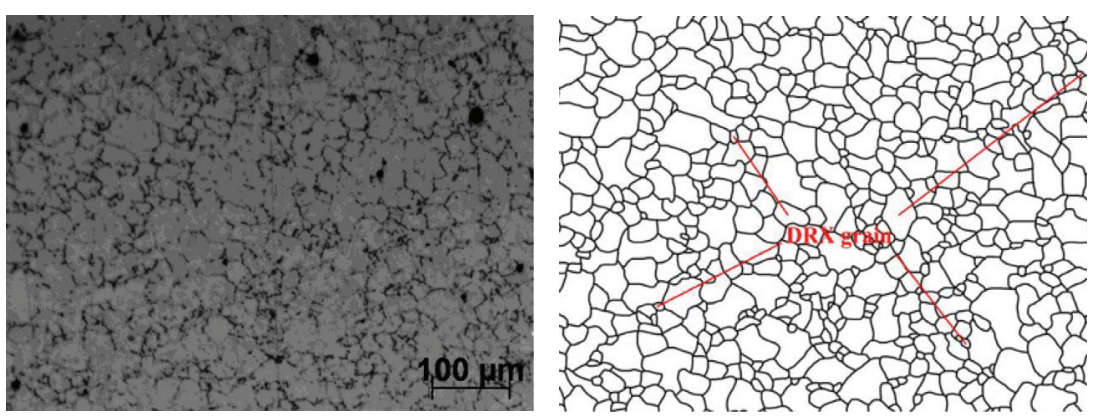

(d)

Figure 9: (Continued).
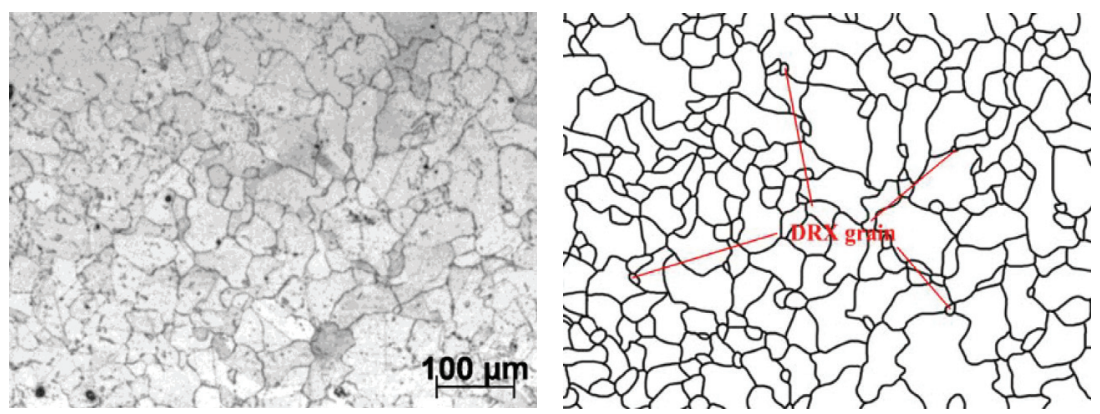

(a)
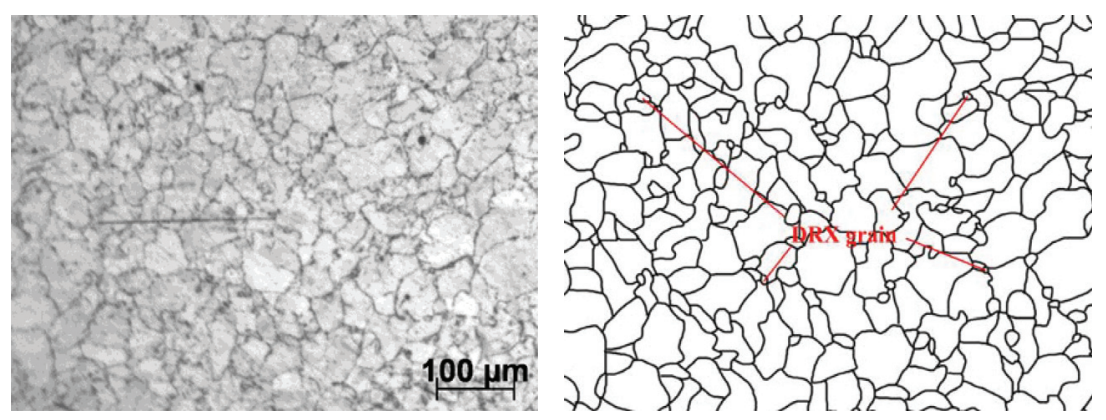

(b)

Figure 10: Optical microstructures of as-extruded 3Cr20Ni10W2 heat-resisting alloy at a fixed true strain of -0.9 , a fixed temperature of 1,353 $\mathrm{K}$ and different strain rates: (a) $0.01 \mathrm{~s}^{-1}$, (b) $0.1 \mathrm{~s}^{-1}$, (c) $1 \mathrm{~s}^{-1}$, (d) $10 \mathrm{~s}^{-1}$. 

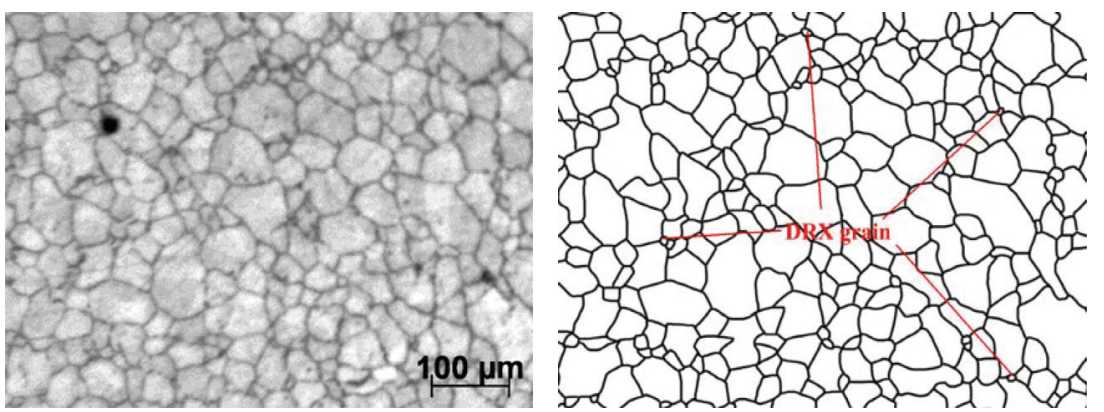

(c)
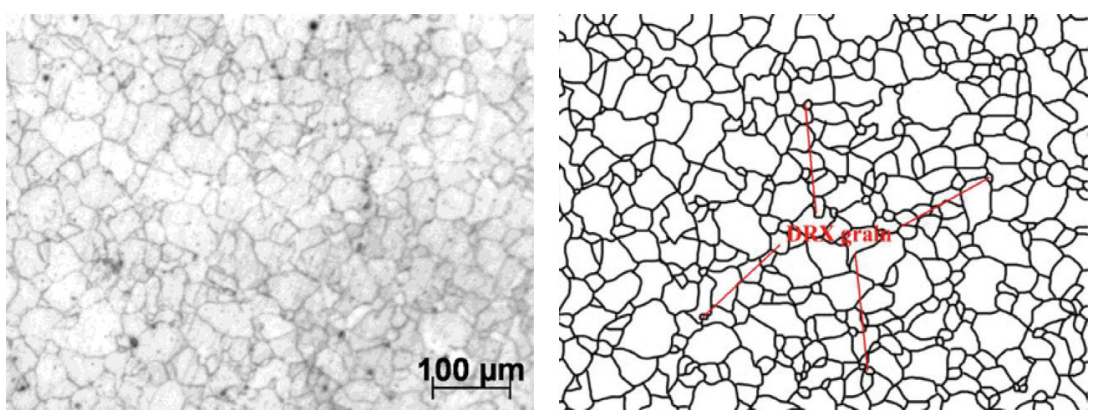

(d)

Figure 10: (Continued).
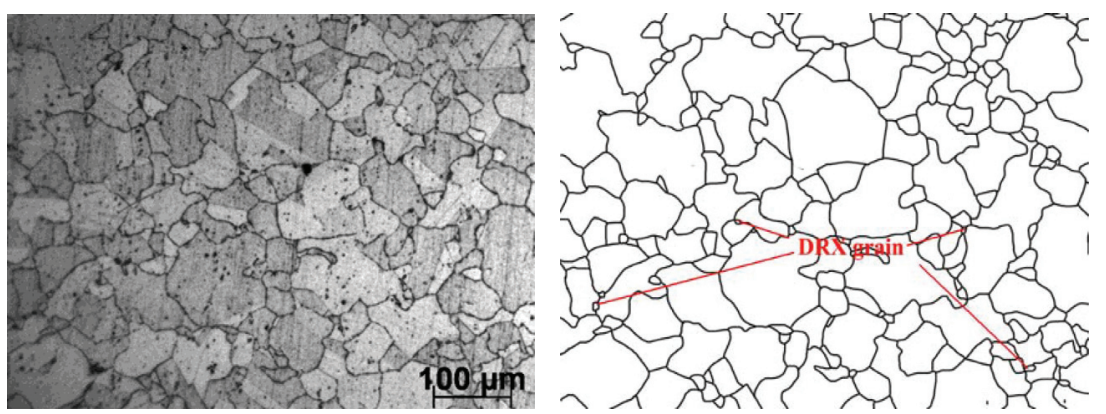

(a)
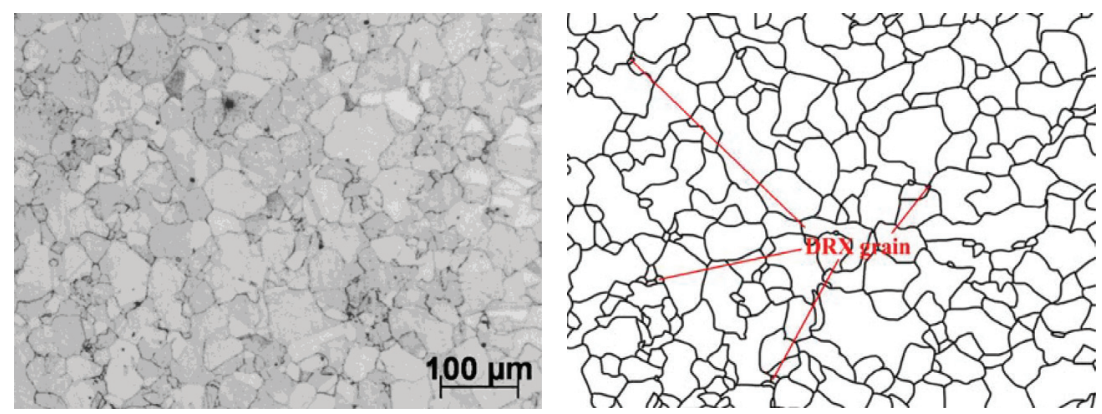

(b)

Figure 11: Optical microstructures of as-extruded 3Cr20Ni10W2 heat-resisting alloy at a fixed true strain of -0.9 , a fixed temperature of 1,403 $\mathrm{K}$ and different strain rates: (a) $0.01 \mathrm{~s}^{-1}$, (b) $0.1 \mathrm{~s}^{-1}$, (c) $1 \mathrm{~s}^{-1}$, (d) $10 \mathrm{~s}^{-1}$. 

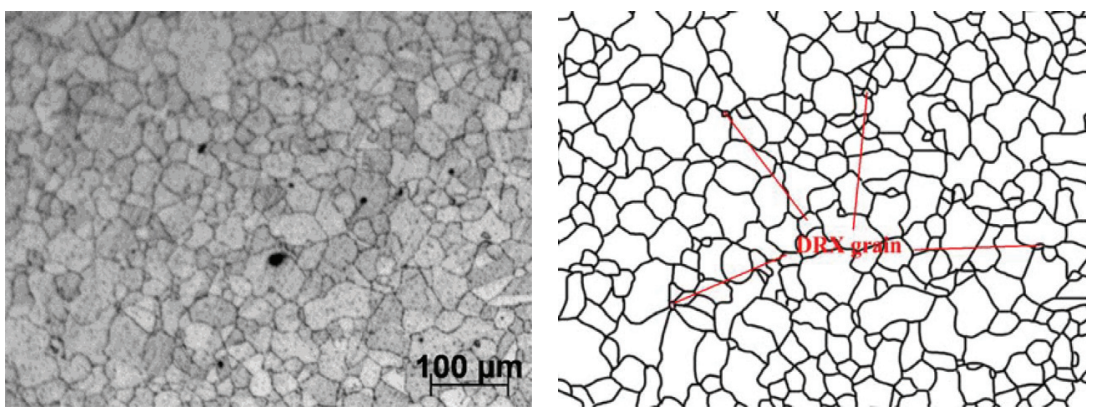

(c)
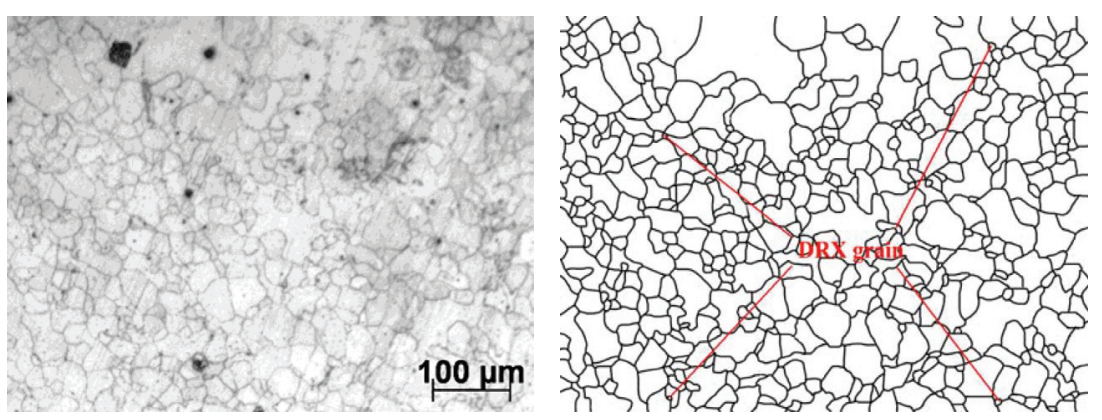

(d)

Figure 11: (Conitnued).

\section{Effect of temperatures and strain rates on average grain size}

Figure 12 shows the grain size distribution of as-extruded 3Cr20Ni10W2 heat-resisting alloy undeformed (starting material). Figures 13-17 show the effects of the strain rate on the grain size distribution of as-extruded 3Cr20Ni10W2 heat-resisting alloy under the true strain of -0.9 and temperatures of 1,203-1,403 $\mathrm{K}$. The average grain size was measured at $2^{\circ}$ intervals and passing through

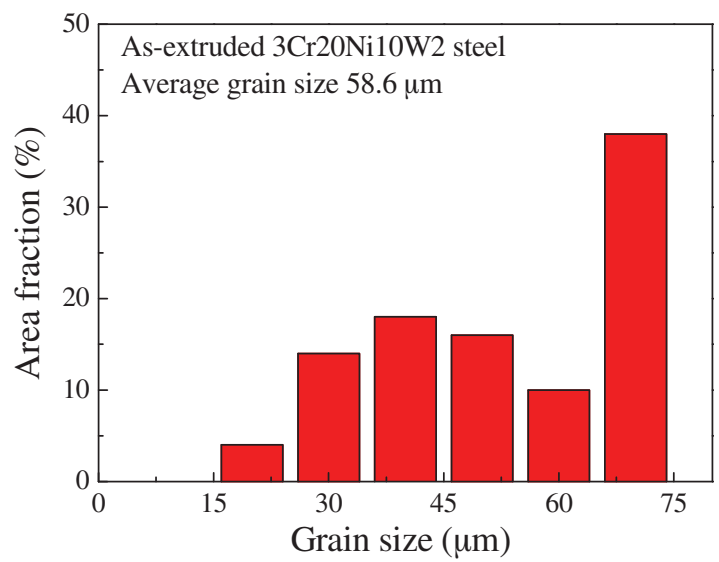

Figure 12: Grain size distribution of as-extruded 3Cr20Ni10W2 heatresisting alloy undeformed (starting material). each grain's centroid. As depicted, under a fixed temperature of $1,203 \mathrm{~K}$ the microstructure of the as-extruded billet with grain size of $58.6 \mu \mathrm{m}$ became refined up to about 22.4 $\mu \mathrm{m}$ after upsetting under strain rate $0.01 \mathrm{~s}^{-1}$, to about 21.5 $\mu \mathrm{m}$ under strain rate $0.1 \mathrm{~s}^{-1}$, to about $20.7 \mu \mathrm{m}$ under strain rate $1 \mathrm{~s}^{-1}$, to about $17.9 \mu \mathrm{m}$ under strain rate $10 \mathrm{~s}^{-1}$. Under a fixed temperature of $1,253 \mathrm{~K}$ the microstructure of the asextruded billet with grain size of $58.6 \mu \mathrm{m}$ became refined up to about $27.9 \mu \mathrm{m}$ after upsetting under strain rate $0.01 \mathrm{~s}$ ${ }^{-1}$, to about $26.4 \mu \mathrm{m}$ under strain rate $0.1 \mathrm{~s}^{-1}$, to about 23.3 $\mu \mathrm{m}$ under strain rate $1 \mathrm{~s}^{-1}$, to about $21.8 \mu \mathrm{m}$ under strain rate $10 \mathrm{~s}^{-1}$. Under a fixed temperature of $1,303 \mathrm{~K}$ the microstructure of the as-extruded billet with grain size of $58.6 \mu \mathrm{m}$ became refined up to about $30.5 \mu \mathrm{m}$ after upsetting under strain rate $0.01 \mathrm{~s}^{-1}$, to about $28.3 \mu \mathrm{m}$ under strain rate $0.1 \mathrm{~s}^{-1}$, to about $18.1 \mu \mathrm{m}$ under strain rate $1 \mathrm{~s}^{-1}$, to about $22.3 \mu \mathrm{m}$ under strain rate $10 \mathrm{~s}^{-1}$. Under a fixed temperature of $1,353 \mathrm{~K}$ the microstructure of the as-extruded billet with grain size of $58.6 \mu \mathrm{m}$ became refined up to about $31.4 \mu \mathrm{m}$ after upsetting under strain rate $0.01 \mathrm{~s}^{-1}$, to about $30.4 \mu \mathrm{m}$ under strain rate $0.1 \mathrm{~s}^{-1}$, to about $30.1 \mu \mathrm{m}$ under strain rate $1 \mathrm{~s}^{-1}$, to about $24.3 \mu \mathrm{m}$ under strain rate $10 \mathrm{~s}^{-1}$. Under a fixed temperature of 1,403 $\mathrm{K}$ the microstructure of the as-extruded billet with grain size of $58.6 \mu \mathrm{m}$ became refined up to about $34.6 \mu \mathrm{m}$ after upsetting under strain rate $0.01 \mathrm{~s}^{-1}$, to about $30.8 \mu \mathrm{m}$ under strain rate $0.1 \mathrm{~s}^{-1}$, to about $28.3 \mu \mathrm{m}$ under strain 


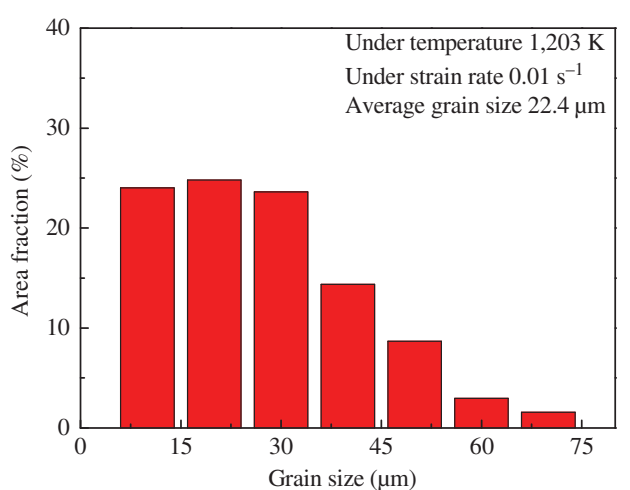

(a)

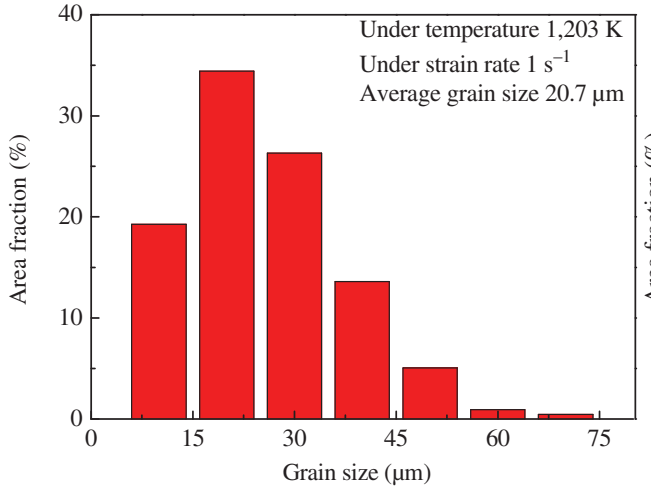

(c)

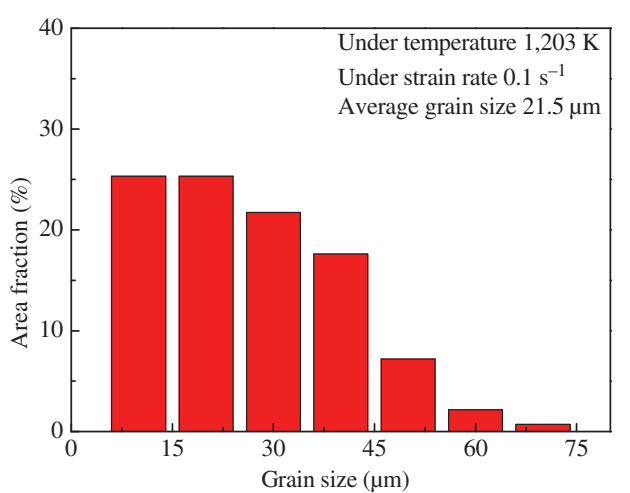

(b)

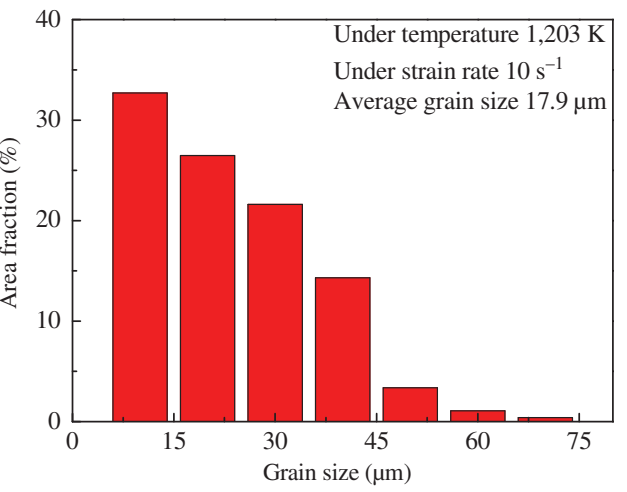

(d)

Figure 13: Grain size distribution of 3Cr20Ni10W2 heat-resisting alloy at a fixed true strain of -0.9 , a fixed temperature of $1,203 \mathrm{~K}$ and different strain rates: (a) $0.01 \mathrm{~s}^{-1}$, (b) $0.1 \mathrm{~s}^{-1}$, (c) $1 \mathrm{~s}^{-1}$, (d) $10 \mathrm{~s}^{-1}$.

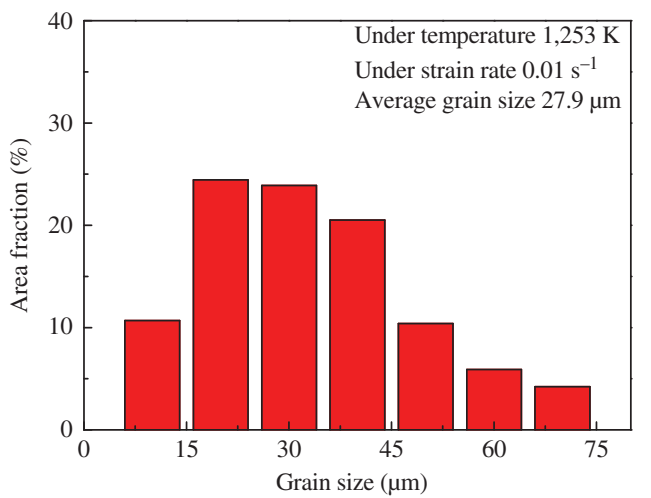

(a)

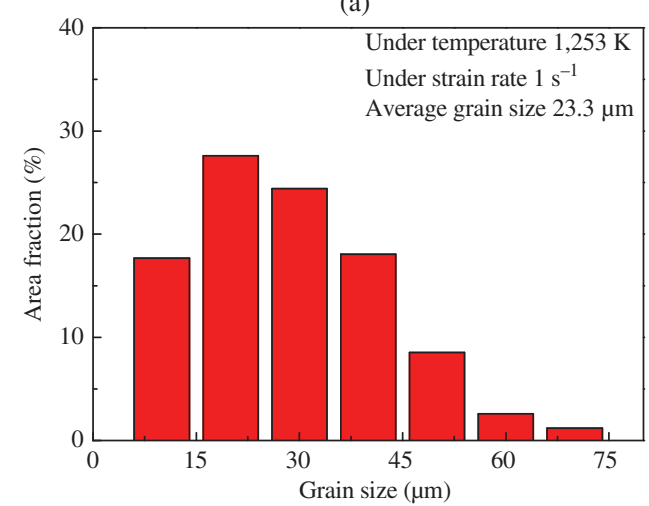

(c)

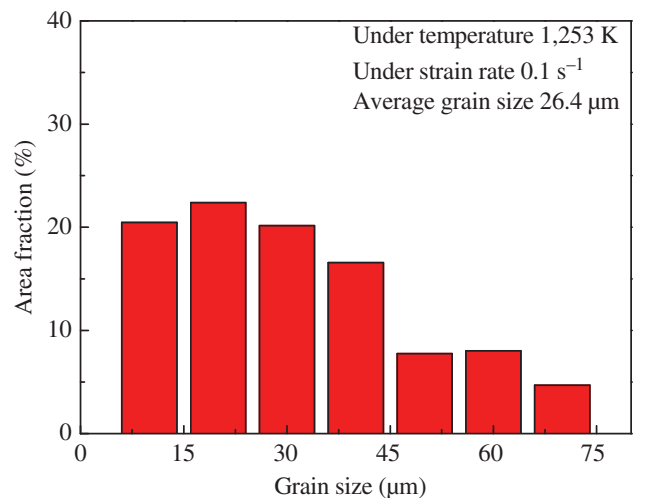

(b)

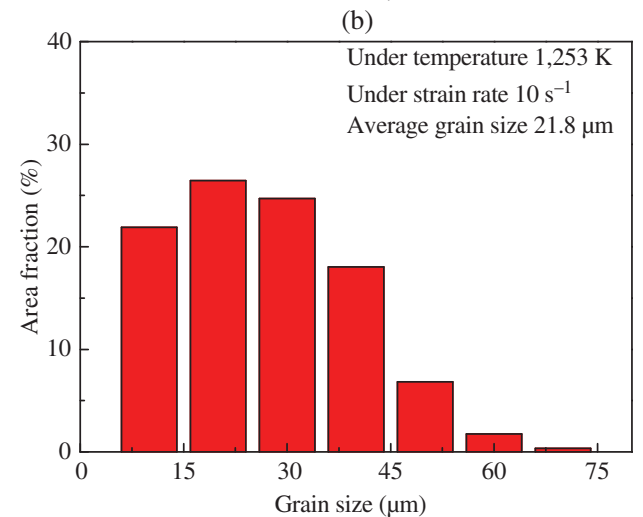

(d)

Figure 14: Grain size distribution of $3 \mathrm{Cr} 20 \mathrm{Ni10W} 2$ heat-resisting alloy at a fixed true strain of -0.9 , a fixed temperature of $1,253 \mathrm{~K}$ and different strain rates: (a) $0.01 \mathrm{~s}^{-1}$, (b) $0.1 \mathrm{~s}^{-1}$, (c) $1 \mathrm{~s}^{-1}$, (d) $10 \mathrm{~s}^{-1}$. 


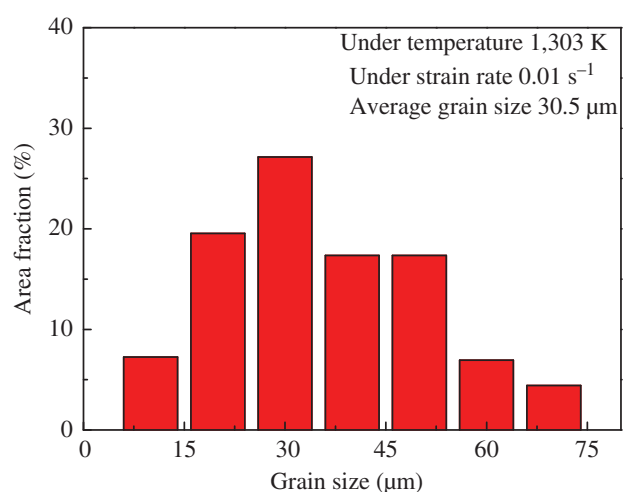

(a)

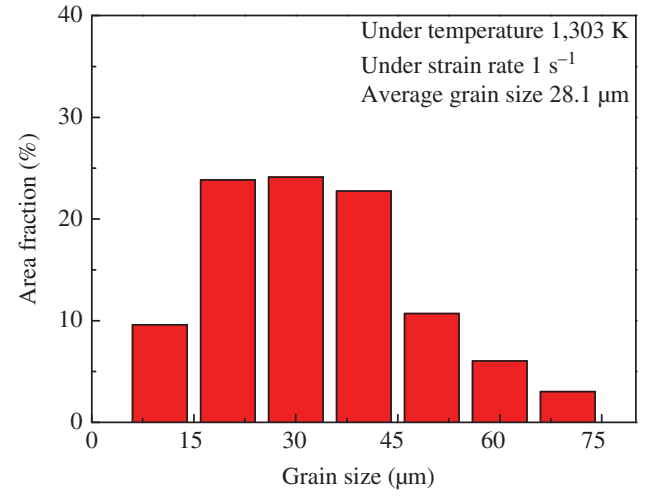

(c)

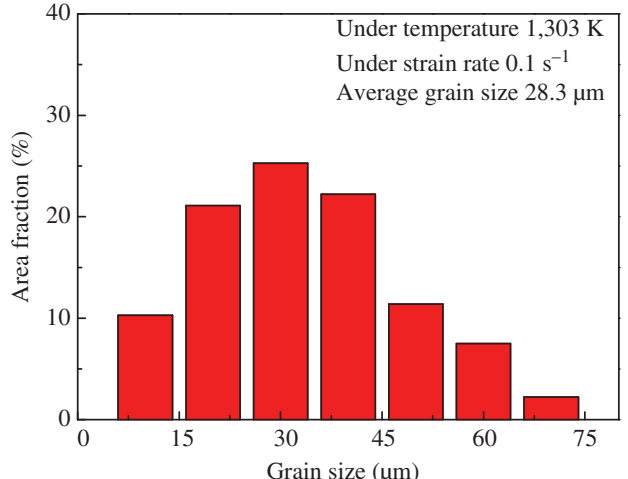

(b)

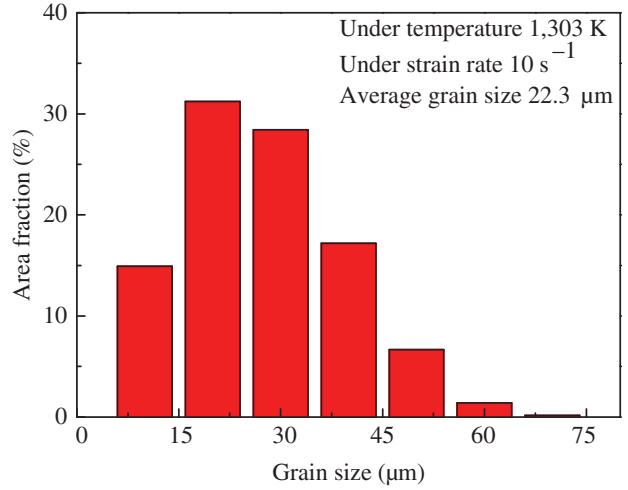

(d)

Figure 15: Grain size distribution of $3 \mathrm{Cr} 20 \mathrm{Ni10 \textrm {W }} 2$ heat-resisting alloy at a fixed true strain of -0.9 , a fixed temperature of $1,303 \mathrm{~K}$ and different strain rates: (a) $0.01 \mathrm{~s}^{-1}$, (b) $0.1 \mathrm{~s}^{-1}$, (c) $1 \mathrm{~s}^{-1}$, (d) $10 \mathrm{~s}^{-1}$.
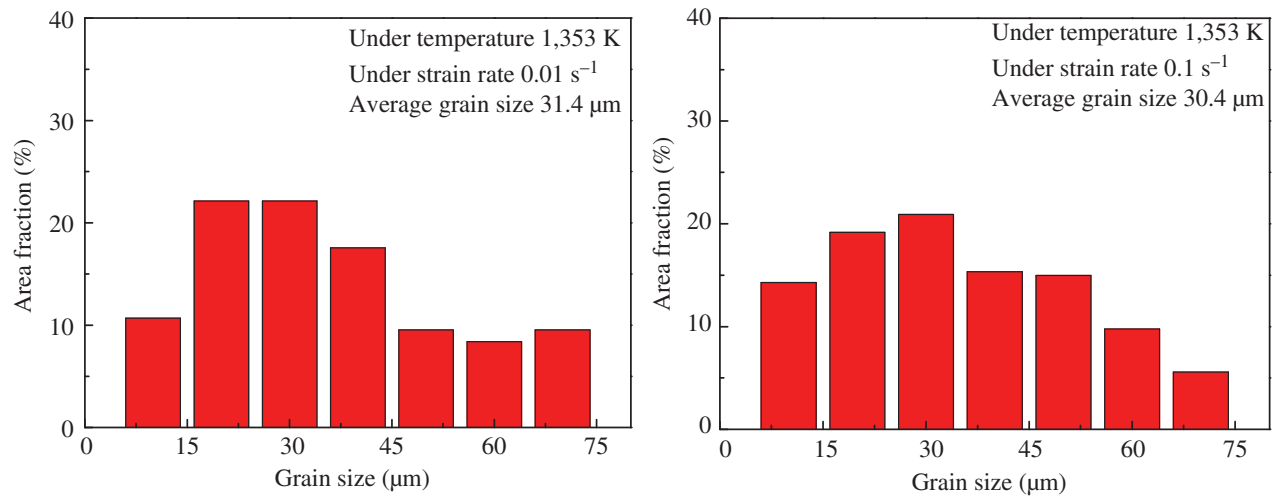

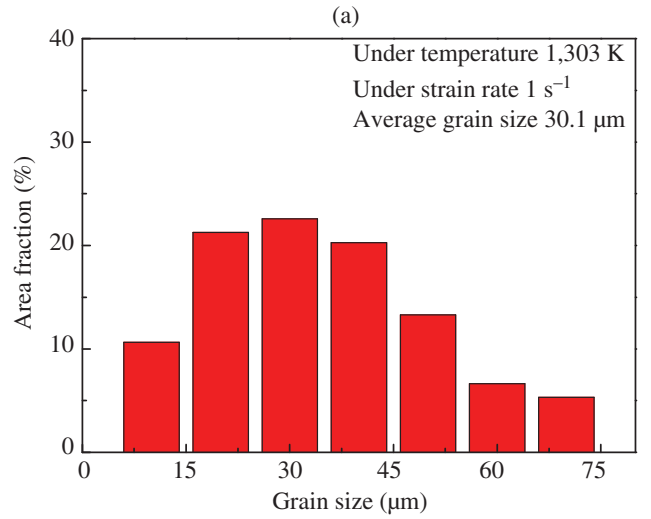

(c)

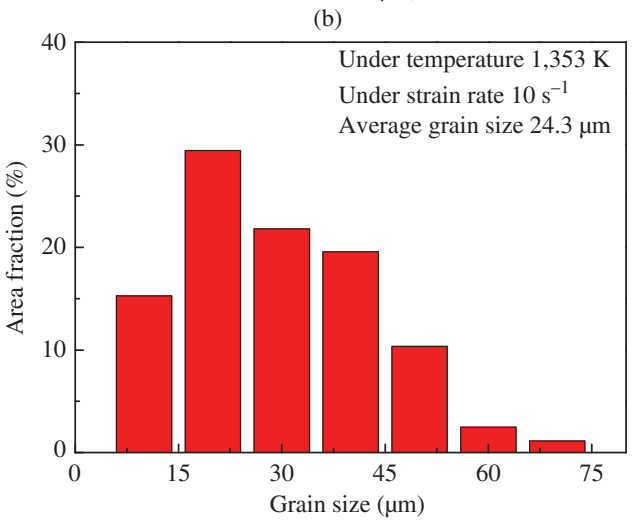

(d)

Figure 16: Grain size distribution of $3 \mathrm{Cr} 20 \mathrm{Ni10W} 2$ heat-resisting alloy at a fixed true strain of -0.9 , a fixed temperature of $1,353 \mathrm{~K}$ and different strain rates: (a) $0.01 \mathrm{~s}^{-1}$, (b) $0.1 \mathrm{~s}^{-1}$, (c) $1 \mathrm{~s}^{-1}$, (d) $10 \mathrm{~s}^{-1}$. 


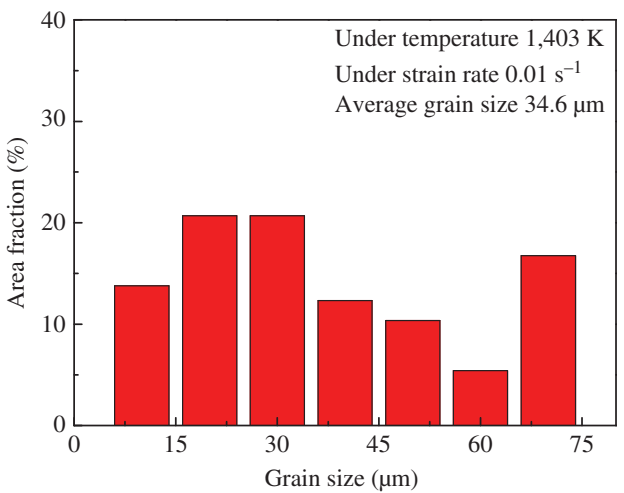

(a)

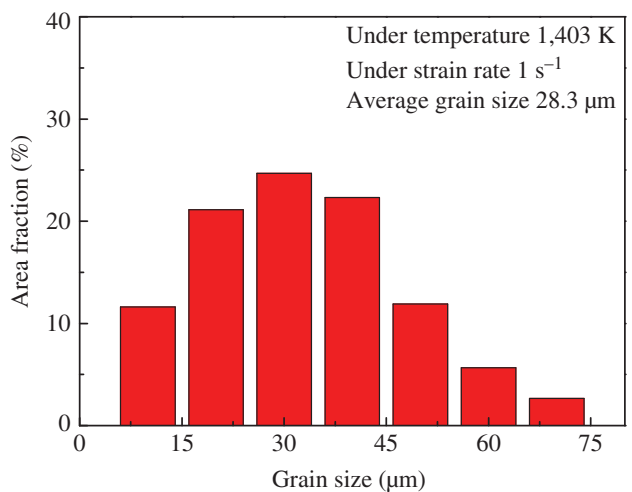

(c)

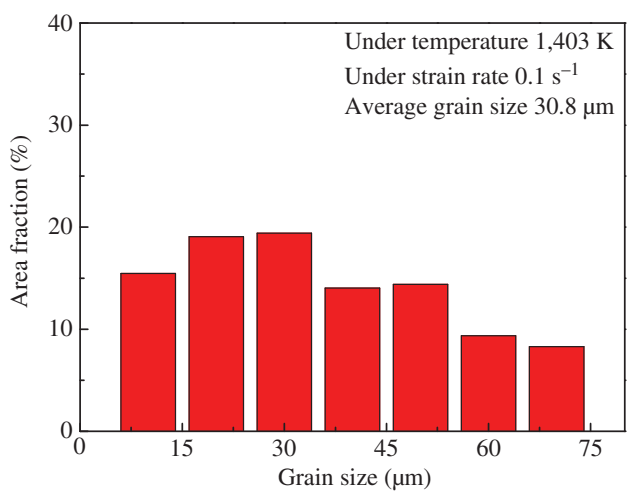

(b)

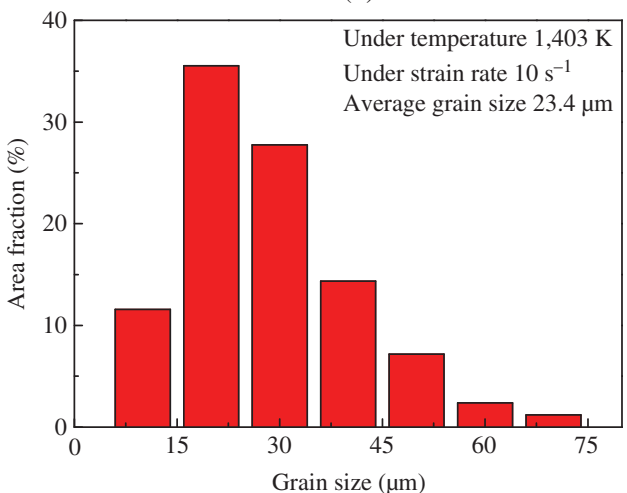

(d)

Figure 17: Grain size distribution of $3 \mathrm{Cr} 20 \mathrm{Ni10W} 2$ heat-resisting alloy at a fixed true strain of -0.9 , a fixed temperature of $1,403 \mathrm{~K}$ and different strain rates: (a) $0.01 \mathrm{~s}^{-1}$, (b) $0.1 \mathrm{~s}^{-1}$, (c) $1 \mathrm{~s}^{-1}$, (d) $10 \mathrm{~s}^{-1}$.

rate $1 \mathrm{~s}^{-1}$, to about $23.4 \mu \mathrm{m}$ under strain rate $10 \mathrm{~s}^{-1}$. It can be summarized that under a fixed temperature, as strain rate increases, the microstructure becomes more and more refined due to increasing stored energy (i.e. high nucleation rate) and decreasing grain growth time [30]. Lin et al. [15] investigated the effects of processing parameters including strain rate, temperature on the microstructures of $42 \mathrm{CrMo}$ steel by metallurgical analysis. The results show that the average grain size of the deformed 42CrMo steel increases with temperature and decreases with strain rate. In our work, the same conclusion has been achieved.

In Figure 12, it can be seen that as for the starting material, the area fraction of large grains with size greater than $60 \mu \mathrm{m}$ is about $38.0 \%$, and the area fraction of finer grains with size less than $30 \mu \mathrm{m}$ is about $18.0 \%$. In Figure 13 corresponding to a fixed temperature of $1,203 \mathrm{~K}$ and different strain rates of $0.01,0.1,1$ and $10 \mathrm{~s}^{-1}$, the area fraction $38.0 \%$ of large grains with size greater than $60 \mu \mathrm{m}$ after upsetting has decreased to about 1.6\%, 0.7\%, 0.5\% and $0.4 \%$, respectively, meanwhile the area fraction $18.0 \%$ of the finer grain with size less than $30 \mu \mathrm{m}$ after upsetting has increased up to $72.4 \%, 72.4 \%, 79.9 \%$ and $80.8 \%$, respectively. In Figure 14 corresponding to a fixed temperature of 1,253 $\mathrm{K}$ and different strain rates of $0.01,0.1$,
1 and $10 \mathrm{~s}^{-1}$, the area fraction $38.0 \%$ of large grains with size greater than $60 \mu \mathrm{m}$ after upsetting has decreased to about $4.2 \%, 4.7 \%, 1.2 \%$ and $0.4 \%$, respectively, meanwhile the area fraction $18.0 \%$ of the finer grain with size less than $30 \mu \mathrm{m}$ after upsetting has increased up to $59.0 \%$, $62.9 \%, 69.6 \%$ and $73.0 \%$, respectively. In Figure 15 corresponding to a fixed temperature of $1,303 \mathrm{~K}$ and different strain rates of $0.01,0.1,1$ and $10 \mathrm{~s}^{-1}$, the area fraction $38.0 \%$ of large grains with size greater than $60 \mu \mathrm{m}$ after upsetting has decreased to about $4.4 \%, 2.2 \%, 3.0 \%$ and $0.2 \%$, respectively, meanwhile the area fraction $18.0 \%$ of the finer grain with size less than $30 \mu \mathrm{m}$ after upsetting has increased up to $53.9 \%, 56.6 \%, 57.5 \%$ and $74.5 \%$, respectively. In Figure 16 corresponding to a fixed temperature of 1,353 $\mathrm{K}$ and different strain rates of $0.01,0.1,1$ and $10 \mathrm{~s}^{-1}$, the area fraction $38.0 \%$ of large grains with size greater than $60 \mu \mathrm{m}$ after upsetting has decreased to about $9.5 \%, 5.5 \%, 5.3 \%$ and $1.1 \%$, respectively, meanwhile the area fraction $18.0 \%$ of the finer grain with size less than 30 $\mu \mathrm{m}$ after upsetting has increased up to $55.0 \%$, 54.4\%, $54.5 \%$ and $66.5 \%$, respectively. In Figure 17 corresponding to a fixed temperature of $1,403 \mathrm{~K}$ and different strain rates of $0.01,0.1,1$ and $10 \mathrm{~s}^{-1}$, the area fraction $38.0 \%$ of large grains with size greater than $60 \mu \mathrm{m}$ after upsetting has 


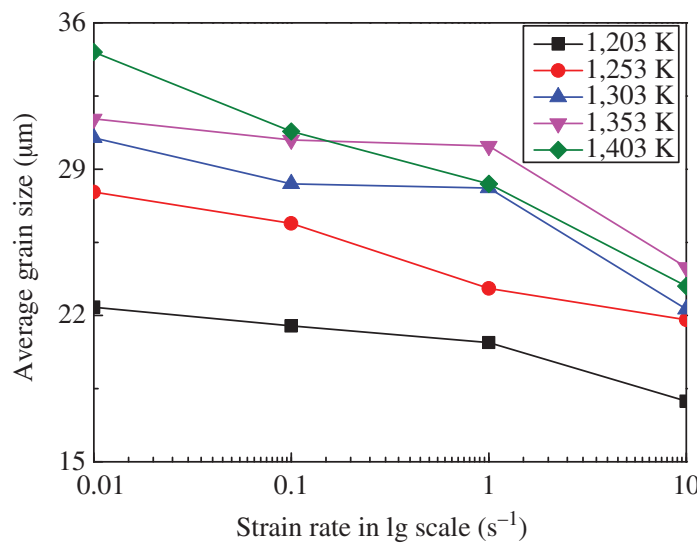

(a)

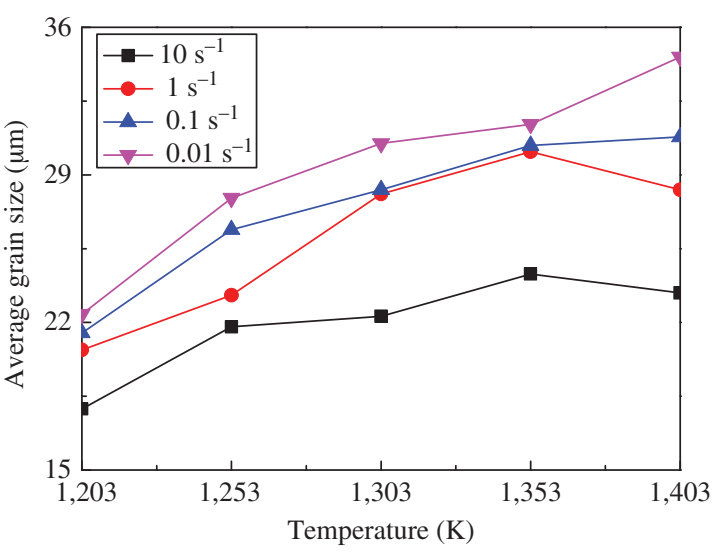

(b)

Figure 18: Changes in average grain size according to (a) strain rate and (b) temperature.

decreased to about $16.7 \%, 8.3 \%, 2.7 \%$ and $1.2 \%$, respectively, meanwhile the area fraction $18.0 \%$ of the finer grain with size less than $30 \mu \mathrm{m}$ after upsetting has increased up to $55.1 \%, 54.0 \%, 57.4 \%$ and $74.9 \%$, respectively. From the above detailed description, it can be concluded that under a fixed temperature, as deformation strain rate increases, the area fraction of large grains becomes smaller and smaller, meanwhile the area fraction of finer grains becomes larger and larger. It is obvious that at a lower strain rate, data set of grain sizes has a larger standard deviation to the average size value, and data spread out over a wide range of values. However, at a larger strain rate, data set of grain sizes has a smaller standard deviation to the average size value, and data have tightly grouped. Further, it can be deduced that as strain rate increases, the microstructure becomes more and more uniform.

In this work, the changes in the average grain size according to deformation temperature and strain rate are shown in Figure 18(a) and (b). As shown in Figure 18(a), the average grain size refined by DRX linearly decreases with increasing strain rate (in log scale). Under higher strain rates, samples preserve a majority of deformation energy, which results in high nucleation rates of recrystallization grains. For a fixed temperature, higher strain rate means that the recrystallized grains have no enough growth time. Thus, more refined grains will be achieved. As shown in Figure 18(b), at a low strain rate, the average grain size rapidly increases with increasing temperature, while it remains almost constant at strain rate of $10 \mathrm{~s}^{-1}$.

\section{Modeling of grain size evolution}

It is generally believed that average grain size $\left(D_{\mathrm{A}}\right)$ decreases with increasing strain rate and decreasing deformation temperature and is independent of initial grain size and accumulated strain. The effects of temperature and strain rate can be expressed in terms of the power law function of Zener-Hollomon parameter, $Z$, in an exponent-type function of temperature and strain rate, as follows [31-33]:

$$
D_{A}=B_{0}+B_{1} \ln Z+B_{2}(\ln Z)^{2}
$$

where $B_{1}$ and $B_{2}$ are polynomial coefficients.

In this work, the variations of average grain size according to different temperatures and strain rates have been achieved. By taking all these results into consideration and an overall analysis, $B_{1}$ and $B_{2}$ are determined by regression analysis as $B_{0}=40.83854$, $B_{1}=0.44614$ and $B_{2}=-0.0076$. Therefore, the formula of average grain size for as-extruded 3Cr20Ni10W2 heatresisting alloy is described as follows:

$$
D_{A}=40.83856+0.44614 \ln Z-0.0076(\ln Z)^{2}
$$

which can be used to predict and control the recrystallized grain size of as-extruded 3Cr20Ni10W2 heat-resisting alloy after hot compression. Figure 19 shows the evolution of average grain size according to $\ln Z$. It is obvious that the average grain size $D_{A}(\mu \mathrm{m})$ decreases with $Z$ parameter rising. According to the description of softening flow behaviors in Section "Characteristics of Softening Flow Behavior Coupling with DRX”, DRX softening is predominant in the deformation parameter window of $1,203-1,253 \mathrm{~K}$ and $0.01 \mathrm{~s}^{-1}, 1,203-1,303 \mathrm{~K}$ and $0.1 \mathrm{~s}^{-1}, 1,203-1,353 \mathrm{~K}$ and $1 \mathrm{~s}^{-1}, 1,203-1,403 \mathrm{~K}$ and $10 \mathrm{~s}^{-1}$, while DRV softening is predominant in the deformation parameter window of 1,303-1,403 $\mathrm{K}$ and $0.01 \mathrm{~s}^{-1}, 1,353-1,403 \mathrm{~K}$ and $0.1 \mathrm{~s}^{-1}, 1,403 \mathrm{~K}$ and $1 \mathrm{~s}^{-1}$. In 


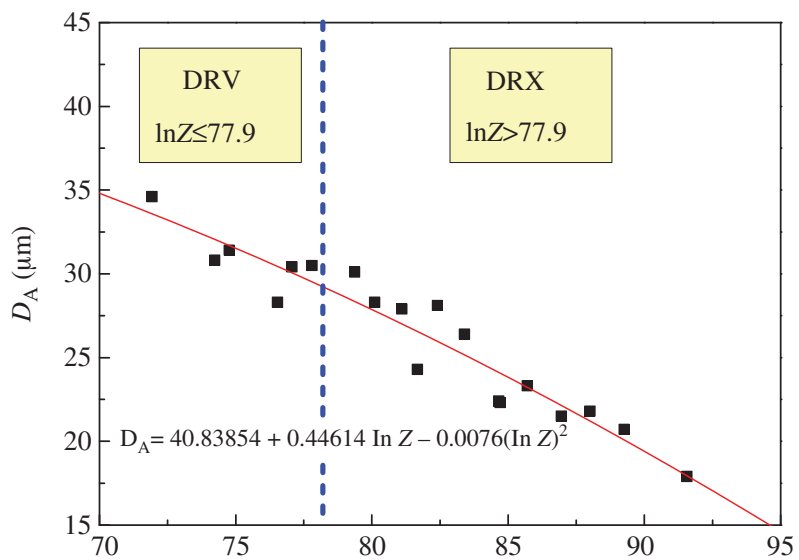

Figure 19: Relationships between average grain size $D_{A}(\mu \mathrm{m})$ and $Z$ parameter.

accordance with the different windows, two regions can be clarified: $\ln Z \leq 77.9$ for DRV region and $\ln Z>77.9$ for DRX region.

\section{Conclusions}

The deformation characteristics of as-extruded 3Cr20Ni10W2 heat-resisting alloy by means of hot compression tests have been investigated in the temperature range of 1,203-1,403 $\mathrm{K}$ and the strain rate range of $0.01-$ $10 \mathrm{~s}^{-1}$. The results are listed below:

1) A typical flow stress curve with DRX is more recognizable at lower temperatures and higher strain rates, and the flow stress level increases with increasing strain rate and decreasing deformation temperature. The types of flow stress evolution were distinguished by the following two characteristics: WH followed by DRX and WH followed by DRV.

2) At a fixed temperature, the average grain size refined by DRX linearly decreases with increasing strain rate (in log scale). At a low strain rate, the average grain size rapidly increases with increasing temperature, while it remains almost constant at a strain rate of $10 \mathrm{~s}^{-1}$.

3) At a lower strain rate, data set of grain sizes has a larger standard deviation to the average size value, and data spread out over a wide range of values. However, at a larger strain rate, data set of grain sizes has a smaller standard deviation to the average size value, and data have tightly grouped. As strain rate increases, the microstructure becomes more and more uniform.
4) The relationships between average grain size and $\ln Z$ were expressed by the equation: $D_{A}=40.83856+$ $0.44614 \ln Z-0.0076(\ln Z)^{2}(\mu \mathrm{m})$, and the average grain size of as-extruded 3Cr20Ni10W2 heat-resisting alloy decreases with the increase of Zener-Hollomon parameter. The regions corresponding to DRX $(\ln Z>77.9)$ and DRV $(\ln Z \leq 77.9)$ have been clarified by $Z$ values.

Acknowledgment: This work was supported by the National Natural Science Foundation of China (51305469).

\section{References}

1. Liu JW, Jiao DL, Luo CP. Microstructural evolution in austenitic heat-resistant cast steel 35Cr25Ni12NNbRE during long-term service. Mater Sci Eng A 2010;527:2772-9.

2. Erneman J, Schwind M, Liu P, Nilsson JO, Andren HO, Agren J. Precipitation reactions caused by nitrogen uptake during service at high temperatures of a niobium stabilised austenitic stainless steel. Acta Mater 2004;52:4337-50.

3. Vach M, Kunikova T, Domankova M, Sevc P, Caplovic L, Gogola $\mathrm{P}$. Evolution of secondary phases in austenitic stainless steels during long-term exposures at 600,650 and $800^{\circ} \mathrm{C}$. J Mater Charact 2008;59:1792-8.

4. Li WY, Yu M, Li JL, Zhang GF, Wang SY. Characterizations of 21-4N to $4 \mathrm{Cr} 9 \mathrm{Si} 2$ stainless steel dissimilar joint bonded by electric-resistance-heat-aided friction welding. Mater Des 2009;30:4230-5.

5. Lin YC, Chen XM. A critical review of experimental results and constitutive descriptions for metals and alloys in hot working. Mater Des 2011;32:1733-59.

6. Lin YC, Chen MS, Zhong J. Numerical simulation for stress/ strain distribution and microstructural evolution in $42 \mathrm{CrMo}$ steel during hot upsetting process. Comput Mater Sci 2008;43:1117-22.

7. Kim SI, Lee Y, Byon SM. Study on constitutive relation of AISI 4140 steel subject to large strain at elevated temperatures. J Mater Process Technol 2003;140:84-89.

8. Quan GZ, Tong Y, Zhou J. Dynamic softening behaviour of AZ80 magnesium alloy during upsetting at different temperatures and strain rates. Proc Inst Mech Eng BJ Eng Manuf 2010;224:1707-16.

9. Momeni A, Dehghani K, Keshmiri H, Ebrahimi GR. Hot deformation behavior and microstructural evolution of a superaustenitic stainless steel. Mater Sci Eng A 2010;527:1605-11.

10. Quan GZ, Mao A, Luo GC, Liang JT, Wu DS, Zhou J. Constitutive modeling for the dynamic recrystallization kinetics of as-extruded 3Cr20Ni10W2 heat-resistant alloy based on stress-strain data. Mater Des 2013;52:98-107.

11. Timoshenkov A, Warczok P, Albu M, Klarner J, Kozeschnik E, Bureau R. Modelling the dynamic recrystallization in C-Mn micro-alloyed steel during thermo-mechanical treatment using cellular automata. Comput Mater Sci 2014;94:85-94

12. Puchi-Cabrera ES, Staia MH, Guérin JD. An experimental analysis and modeling of the work-softening transient due to dynamic recrystallization. Int J Plast 2013;54:113-31. 
13. Li H, Wu C, Yang H. Crystal plasticity modeling of the dynamic recrystallization of two-phase titanium alloys during isothermal processing. Int J Plast 2013;51:271-91.

14. Fang JX. Study on Controlling Austenitic Grain Size and Carbide in SNCrW Steel. Heat Treat 2009;24:58-61.

15. Lin YC, Chen MS. Microstructural evolution in 42CrMo steel during compression at elevated temperatures. J Comput Mater Sci 2008;62:2132-5.

16. Lin YC, Deng J, Jiang YQ, Wen DX, Liu G. Hot tensile deformation behaviors and fracture characteristics of a typical Ni-based superalloy. Mater Des 2014;55:949-57.

17. Haghdadi N, Zarei-Hanzaki A, Abou-Ras D, Maghsoudi MH, Ghorbani A. An investigation into the homogeneity of microstructure, strain pattern and hardness of pure aluminum processed by accumulative back extrusion. Mater Sci Eng A 2014;595:179-87.

18. Zhu YZ, Wang SZ, Li BL, Yin ZM, Wan Q, Liu P. Grain growth and microstructure evolution based mechanical property predicted by a modified Hall-Petch equation in hot worked Ni76Cr19AlTiCo alloy. Mater Des 2014;55:456-62.

19. Shafaat MA, Omidvar H, Fallah B. Prediction of hot compression flow curves of Ti-6Al-4V alloy in $\mathrm{a}+\mathrm{b}$ phase region. Mater Des 2011;32:4689-95.

20. Quan GZ, Lv WQ, Mao YP, Zhang YW, Zhou J. Prediction of flow stress in a wide temperature range involving phase transformation for as-cast Ti-6Al-2Zr-1Mo-1V alloy by artificial neural network. Mater Des 2013;50:51-61.

21. Mandal S, Mishra SK, Kumar A, Samajdar I, Sivaprasad PV, Jayakumar T, et al. Evolution and characterization of dynamically recrystallized microstructure in a titanium-modified austenitic stainless steel using ultrasonic and EBSD techniques. Philos Mag 2008;88:883-97.

22. Mandal S, Bhaduri AK, Sarma VS. A study on microstructural evolution and dynamic recrystallization during isothermal deformation of a Ti-modified austenitic stainless steel. Metall Mater Trans A 2011;42:1062-72.

23. Mandal S, Bhaduri AK, Sarma VS. Influence of state-of-stress on dynamic recrystallization in a Ti-modified austenitic stainless steel. Metall Mater Trans A 2012;43:410-14.
24. Mandal S, Sivaprasad PV, Sarma VS. Dynamic recrystallization in a Ti modified austenitic stainless steel during high strain rate deformation. Mater Manuf Processes 2010;25:54-59.

25. Quan GZ, Li GS, Chen T, Wang YX, Zhang YW, Zhou J. Dynamic recrystallization kinetics of $42 \mathrm{CrMo}$ steel during compression at different temperatures and strain rates. Mater Sci Eng A 2011;528:4643-51.

26. Čička R, Bakajová J, Štefániková M, Dománková $M$, Janovec J. Evolution of secondary phases in $0.17 \mathrm{C}-16 \mathrm{Cr}-11 \mathrm{Mn}$ $0.43 \mathrm{~N}$ austenitic stainless steel at 800 and $850^{\circ} \mathrm{C}$ : Thermodynamic modeling of phase equilibria and experimental kinetic studies. J Min Metall B 2012;48:403-11.

27. Kaneko K, Fukunaga T, Yamada K, Nakada N, Kikuchi M, Saghi Z, et al. Formation of M23C6-type precipitates and chromium-depleted zones in austenite stainless steel. Scr Mater 2011;65:509-12.

28. García C, de Andre's G, Caruana LFA. Control of M23C6 carbides in $0.45 \mathrm{C}-13 \mathrm{Cr}$ martensitic stainless steel by means of three representative heat treatment parameters. Mater Sci Eng A Struct Mater 1998;241:211-5.

29. Hong CM, Shi J, Sheng LY, Cao WC, Hui WJ, Dong H. Effects of hot-working parameters on microstructural evolution of high nitrogen austenitic stainless steel. Mater Des 2011;32:3711-7.

30. Mandal S, Bhaduri AK, Sarma VS. Role of twinning on dynamic recrystallization and microstructure during moderate to high strain rate hot deformation of a Ti-modified austenitic stainless steel. Metall Mater Trans A 2012;43:2056-68.

31. Imbert CAC, McQueen HJ. Dynamic recrystallization of $A 2$ and $M 2$ tool steels. Mater Sci Eng A 2001;313:104-16.

32. Salvatori I, Inoue T, Nagai K. Ultrafine grain structure through dynamic recrystallization for Type 304 stainless steel. ISIJ Int 2002;42:744-50.

33. Mao PL, Su GY, Yang K. Dynamic recrystallisation of as cast austenite in 18-8 stainless steel. Mater Sci Technol 2002;18:892-6. 